\title{
Archeological 3D Mapping: The Structure from Motion Revolution
}

Mark D. Willis

Sacred Sites Research, Inc

Charles W. Koenig

Ancient Southwest Texas Project, Texas State University

Stephen L. Black

Department of Anthropology, Texas State University

Amanda M. Castañeda

Ancient Southwest Texas Project, Texas State University

Follow this and additional works at: https://scholarworks.sfasu.edu/ita

Part of the American Material Culture Commons, Archaeological Anthropology Commons, Environmental Studies Commons, Other American Studies Commons, Other Arts and Humanities Commons, Other History of Art, Architecture, and Archaeology Commons, and the United States History Commons

Tell us how this article helped you.

This Article is brought to you for free and open access by the Center for Regional Heritage Research at SFA ScholarWorks. It has been accepted for inclusion in Index of Texas Archaeology: Open Access Gray Literature from the Lone Star State by an authorized editor of SFA ScholarWorks. For more information, please contact cdsscholarworks@sfasu.edu. 


\section{Archeological 3D Mapping: The Structure from Motion Revolution}

\section{Licensing Statement}

Reproduction, posting, transmission, or other distribution or use of the Journal volume, individual article or any portion of the material therein, in any medium, is permitted strictly for personal, non-commercial purposes via a personal-use exemption under a Creative Commons license granted by JTAH.org, Inc. This license exemption requires, as a condition of its granted permission, proper credit be attributed to JTAH.org as copyright holder (e.g., Journal of Texas Archeology and History.org @ 2017). No part of this publication may be reproduced, posted, transmitted, or otherwise utilized or distributed in any form by any means or method for commercial purposes without the express written consent of the Publisher.

Inquiries should be addressed to JTAH Publisher, Suite 307, Box 361, 5114 Balcones Woods Drive, Austin, Texas, 78759.

The Journal of Texas Archeology and History.org is an organization dedicated to furthering research, education and public outreach in the fields of archeology and history concerning Texas and its bordering states of Louisiana, Arkansas, Oklahoma, New Mexico and Northern Mexico; a region we call the "Texas Borderlands." The J.T.A.H. is collaborating with the Index of Texas Archaeology and S.F.A.S.U. to distribute their publication library to the general public via free and open-access channels. Visit www.JTAH.org to submit an article. 


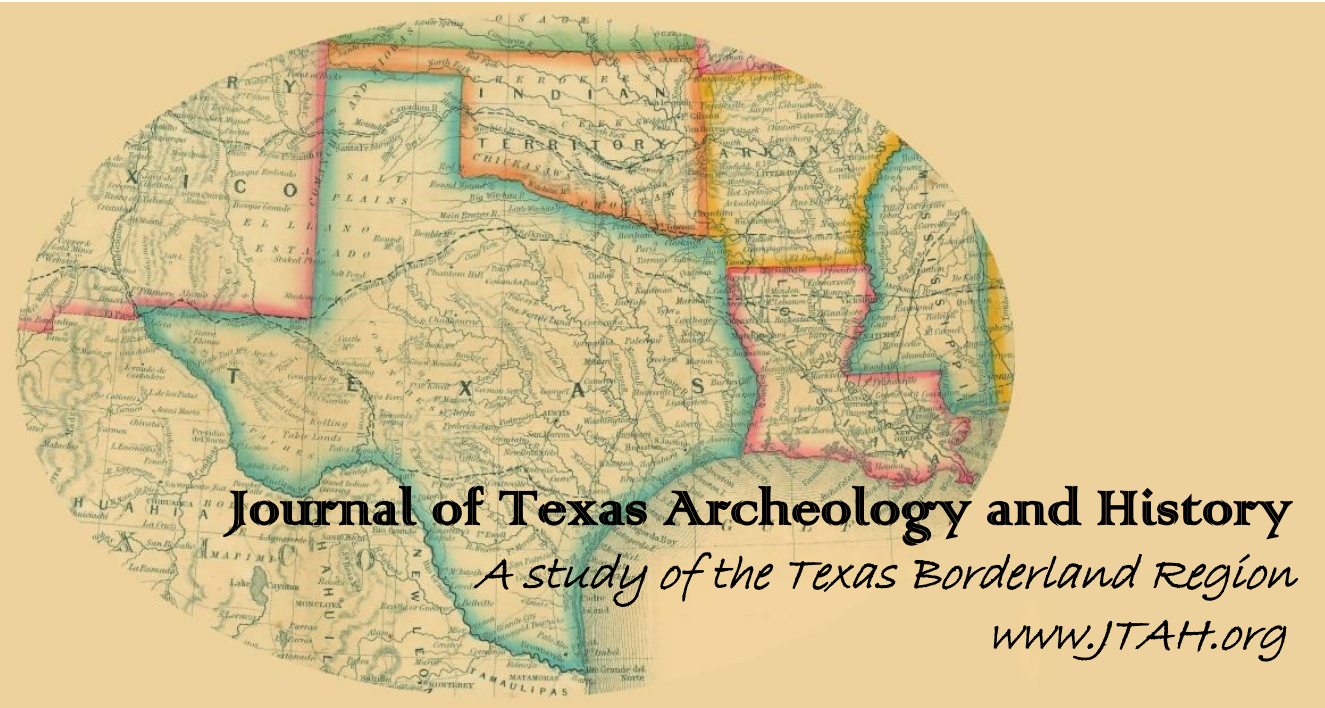

\title{
Article Title: ARCHEOLOGICAL 3D MAPPING: THE STRUCTURE FROM MOTION REVOLUTION
}

\author{
Author(s): $\quad$ Mark D. Willis, Charles W. Koenig, Stephen L. Black, and Amanda M. Castañeda
}

Original Source: J.T.A.H. Volume 3 (2016/2017), Article 1, pp. 1-36; online 04 June 2016

Recommended Citation: Willis, Mark D., Charles W. Koenig, Stephen L. Black, and Amanda M.

Castañeda; "Archeological 3D Mapping: The Structure from Motion Revolution", (2017), Journal of Texas Archeology and History Volume 3 (2016/2017), pp. 1-36.

Copyright (C 2017 by Journal of Texas Archeology and History.org, Inc. All rights reserved. Online/Digital publication: ISSN 2334-1874

The online, digital, and print versions of the publication "Journal of Texas Archeology and History" are published by Journal of Texas Archeology and History.org, Inc., a Texas nonprofit IRC Section 501(c)(3) corporation.

Reproduction, posting, transmission, or other distribution or use of the Journal volume, individual article or any portion of the material therein, in any medium, is permitted strictly for personal, non-commercial purposes via a personal-use exemption under a Creative Commons license granted by JTAH.org, Inc. This license exemption requires, as a condition of its granted permission, proper credit be attributed to JTAH.org as copyright holder (e.g., Journal of Texas Archeology and History.org (C) 2017). No part of this publication may be reproduced, posted, transmitted, or otherwise utilized or distributed in any form by any means or method for commercial purposes without the express written consent of the Publisher. Inquiries should be addressed to JTAH Publisher, Suite 307, Box 361, 5114 Balcones Woods Drive, Austin, Texas, 78759.

The Journal of Texas Archeology and History.org is an organization dedicated to furthering research, education and public outreach in the fields of archeology and history concerning Texas and its bordering states of Louisiana, Arkansas, Oklahoma, New Mexico and Northern Mexico; a region we call the "Texas Borderlands." The J.T.A.H. is collaborating with the Index of Texas Archaeology and S.F.A.S.U. to distribute their publication library to the general public via free and open-access channels. Visit www.JTAH.org to submit an article. 


\title{
ARCHEO LO GICAL 3D MAPPING: THE STRUCTURE FROM MOTION REVOLUTION
}

\author{
Mark D. Willis ${ }^{1}$, Charles W. Koenig ${ }^{2 *}$, Stephen L. Black ${ }^{2}$, and Amanda M. Castañeda ${ }^{2}$
}

\begin{abstract}
Mapping is a critical aspect of systematic documentation no matter where archaeologists work. From hand-drawn maps of excavation units to maps created with Total Data Stations or LiDAR scanning, today's archaeologists have a suite of mapping techniques and technologies to choose from when documenting a site. Typically, spectacular sites often receive high resolution mapping, whereas everyday sites rarely do. Recently, however, a revolutionary technology and technique has been created that can produce highly accurate and precise three-dimensional maps and orthophotos of archaeological sites, features, and profiles at a fraction of the cost and time of LiDAR and intensive TDS mapping: Structure from Motion (SfM). SfM is a new digital photography processing technique for capturing highly detailed, three-dimensional (3D) data from almost any surface using digital cameras. This article introduces the various platforms SfM photographs can be collected from (UAV, kites, balloons, poles, and groundbased) and provides examples of different types of data SfM can provide. The Structure from Motion Revolution is unfolding across the globe at a rapid pace, and we encourage archaeologists to take advantage of this new recording method.
\end{abstract}

\section{INTRODUCTION}

Mapping is a cornerstone of systematic archeological excavation, documentation, and interpretation. Site reports and articles characteristically include two-dimensional maps of excavation units, profiles, features, artifact distributions, and other spatial data. Mapping using Total Data Stations (TDS) is common and capable of producing very accurate site maps. But TDS mapping is time consuming, and the larger and more topographically varied the site the more time required particularly if high resolution is desired. The use of LiDAR has become commonplace within archeology in the past decade, yet laser mapping is expensive, and most everyday archeological sites never receive the same detailed mapping as sites with monumental architecture. At the scale of the ordinary excavation unit and trench profile, most archeologists still either settle for a quick, minimally detailed sketch and a few photos or, for critical subjects, laboriously create maps and section drawings

${ }^{1}$ Blanton and Associates, Austin, TX 78734

${ }^{2}$ Department of Anthropology, Texas State University, San Marcos, Texas 78666

*Corresponding Author (ck1286@txstate.edu)

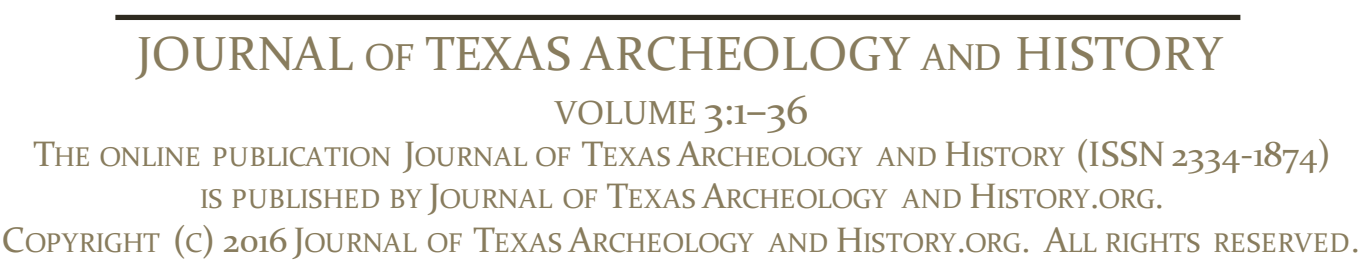


using graph paper and taped measurements and/or stitch together photo mosaics that are unavoidably distorted. Fortunately, there is a new technology and technique that can produce highly accurate and precise (see Green et al. 2014) three-dimensional maps and orthophotos of archeological sites, features, and sections (profiles) at a fraction of the cost and time of LiDAR and TDS mapping: Structure from Motion photogrammetry.

Structure from Motion (SfM) photogrammetry is a new digital photography processing technique for capturing highly detailed, three-dimensional (3D) data from almost any surface using digital cameras. Using SfM, archeologists can produce topographic maps, orthophotos, digital elevation models (DEMs), and 3D renderings of landscapes, features, excavation units, stratigraphic profiles, buildings, cave walls, or countless other surfaces. Willis first demonstrated the usefulness of SfM in producing 3D models in April 2009 when he posted a short video on YouTube of a 3D model of a prehistoric stacked-stone circle in West Texas (http://youtu.be/TuHJUS2olyc). The video went viral and over the following months Willis and other "geeks" from across the world refined the process using archeological data (Willis 2010). Companies such as AutoDesk and AgiSoft quickly developed commercial products that made the process more user friendly and widely applicable. Archeologists soon after began to use SfM on various projects across Texas and around the world (e.g., Brown et al. 2010; De Reu et al. 2014; De Reu et al. 2013; Douglass et al. 2015; Kenmotsu et al. 2012; Liebman et al 2013; Miller et al. 2012; Willis and Jalandoni 2011).

This article is intended to introduce SfM methodology to a wider audience, provide a variety of case studies highlighting the different ways the method can be applied to archeological projects, and urge archeologists in all field settings to immediately begin capturing the underlying input data - sets of overlapping, multidirectional digital photographs. Regardless of the subject being mapped, from landscapes to sites to small features, SfM represents an extraordinary revolution in archeological documentation and the methods used are applicable wherever archeologists work. Even if you lack the time, resources, or motivation to actually create SfM models, there is every reason to begin collecting and archiving the basic input data, namely large sets of overlapping digital images. Archeology is inherently destructive and technological innovations such as SfM will allow us to create visual and 3D data archives of what we have destroyed (De Reu et al. 2013; De Reu et al. 2014).

\section{STRUCTURE FROM MOTION}

There are three general steps to the creation of a 3D model using SfM: 1) collect dozens to hundreds of overlapping photographs of the subject using a digital camera; 2) load these photographs into a specialized software that can match these photographs together to construct a 3D model; and 3 ) use coordinates from ground control points to reference the model in $3 \mathrm{D}$ space.

\section{Taking Photographs for SfM}

Sets of digital photographs serve as the underlying data for any Structure from Motion 3D model. Depending on the size of the subject or desired resolution of the subsequent 3D model, SfM photo sets can range from less than a dozen to several thousand. Individually, each of these photographs must 
minimally overlap 30 percent vertically and horizontally to ensure the software can create the $3 \mathrm{D}$ surface (Figure 1). For any single point to be modeled within a scene, it must be visible in a minimum of three photographs. To maintain sufficient overlap and ensure everything is photographed, we prefer the "snake" method of photographing, where the photographer begins at one point and moves back and forth around the subject in a logical manner (Figure 2). In this way every photograph shares content with photographs before and after, similar to creating a flip book. When using the snake method it is also best to plan out the photographic route prior to beginning photography. Such planning allows the photographer to physically move around the subject and take the photographs in a logical succession.

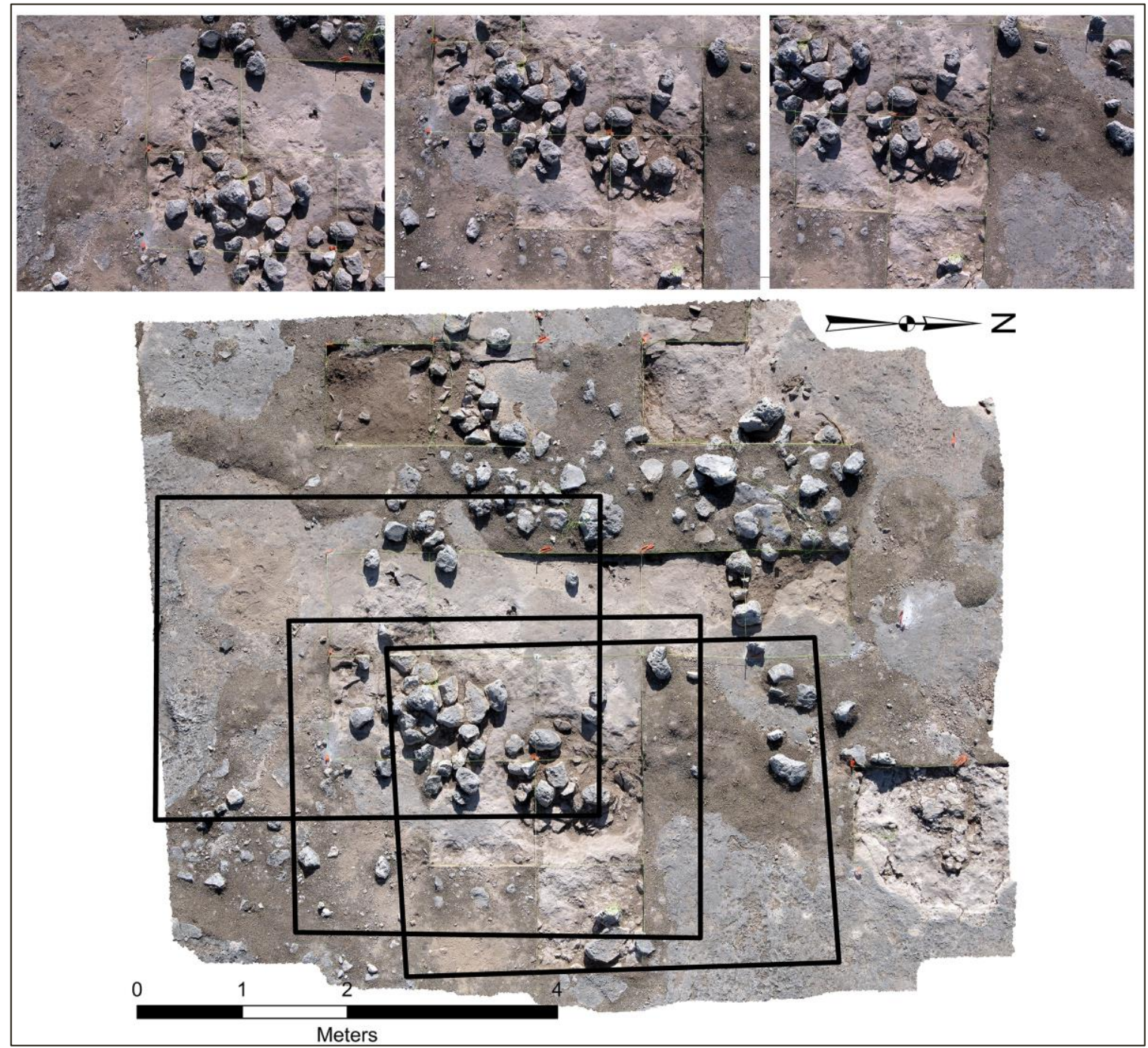

Figure 1. 3D surface of the central stone alignmentat Javelina Heights (41VV2005) generated from 25 overlapping photographs collected using Pole Aerial Photography. The 3D surface of the central stone alignment (bottom) shown with the superimposed locations of the top photographs. 

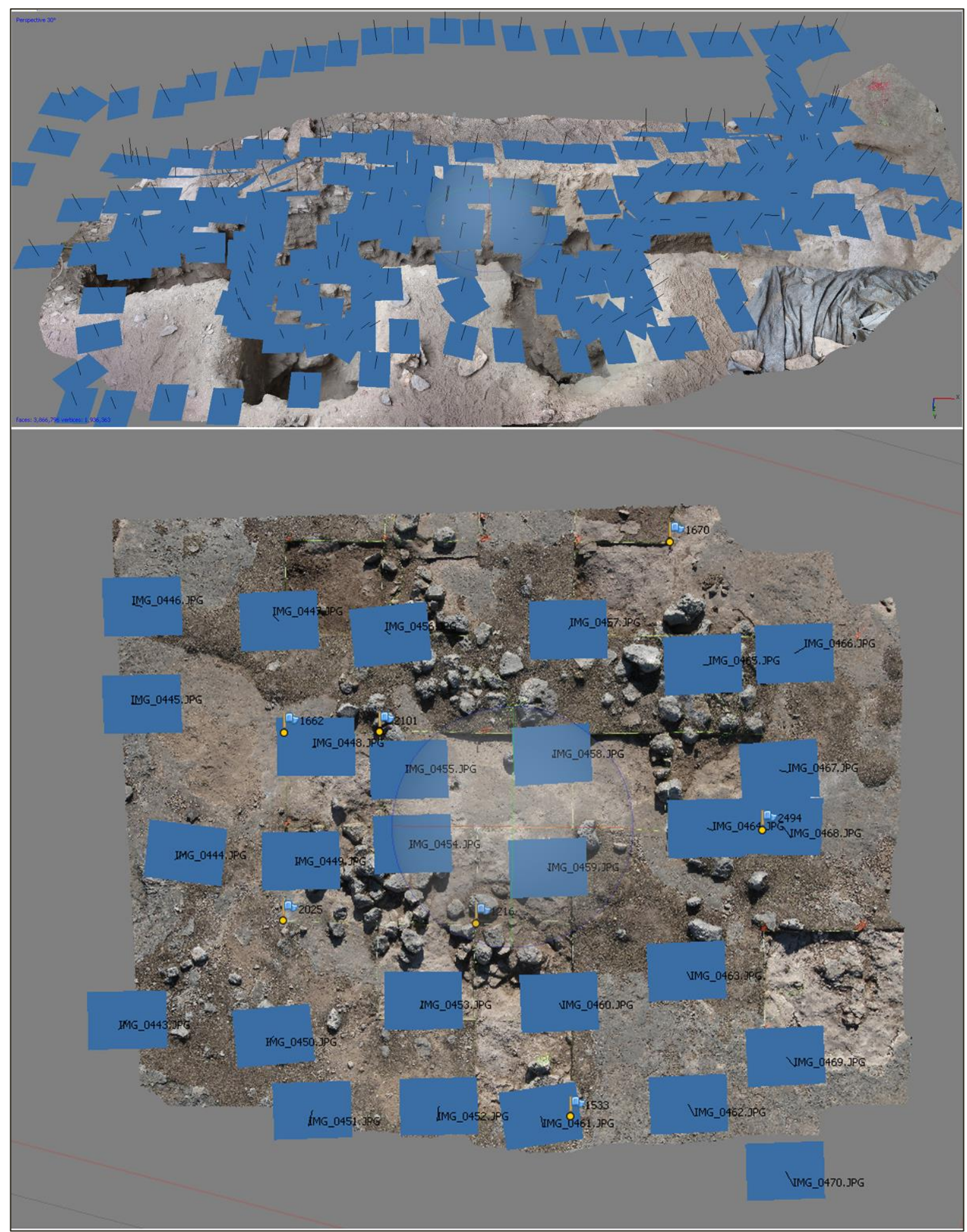

Figure 2. Locations of photograph center points (blue squares) shown relative to the 3D surfaces from Skiles Shelter (41VV165, top) and Javelina Heights (41VV2005, bottom) in AgiSoftPhotoscan. The 3D model of Skiles Shelter was generated from 250 photographs, and the 3D model of Javelina Heights from 25 photographs. Ground-based methods (top) allow for photographing complex surfaces from the ground, and result in a dense overlapping set of photos. Aerial methods (bottom) resultin photographs that are more evenly distributed over the surface. Both sets of photographs were collected in a logical manner and traverse the subject in a "snake" pattern, with each photograph maintaining 30 $60 \%$ overlap. 
These are just basic principles to keep in mind when collecting SfM photographs. Modifications to the basic technique for gathering photographs will be necessary depending on the size of the subject, the orientation of the subject (e.g., horizontal versus vertical surfaces), the level of detail needed from the final results, site conditions, and available platforms for taking photographs. For instance, when photographing objects with complex geometry, like an excavation unit with large rocks protruding from the walls, additional photographs of unit corners and around all sides of the rocks will be necessary. This is because as the camera moves, the perspective of each shape or angle changes significantly. With unit corners and jutting objects an increase in overlap from 30 to 50 percent is often required to ensure sufficient coverage. The most common problem with complex surfaces is not taking enough photographs. Learning how many photographs to take and maintaining sufficient overlap is the greatest challenge for those learning the method.

Other critical requirements when taking SfM photos are that the subject be mostly static and have a natural texture. Glass or shiny metal does not model well because the surfaces are very reflective, hampering the program's ability to match points within the photographs. In our experience, if a puddle of water or highly reflective metal surface is included in the SfM sets, that surface will become empty space in the resulting 3D model. SfM also requires relatively stable environments to create $3 \mathrm{D}$ models. In other words, strong changes in lighting conditions (shadow to light) or movement within the scene (vegetation or flagging tape blowing in the wind) will prevent the software from matching the photographs in certain areas. By shading the subject, taking photographs when the lighting is even, and not taking photographs when strong winds are creating movement, one can minimize the adverse effects of lighting and changing vegetation. Thus, SfM may not work well for modeling individual lithic tools, glass objects, or dense vegetation. While there are some techniques that can allow SfM to model even these objects (see Willis et al. 2014), it is often more efficient to consider using a laser or structure light scanner in such circumstances. One final imperative is that the SfM photographs themselves should be clear (i.e., in focus). Blurry photos caused by poor camera settings, unstable footing for the photographer, or rushed photography can cause distortions in the 3D model and/or prevent the software from matching together the photos. The best way to minimize blurry photos is become familiar with adjusting the camera's settings to compensate for changing conditions, and by taking photographs from a stable platform.

It may seem as though taking SfM photograph sets would be time consuming, but in reality with experience and decent equipment the process is quite fast, especially compared to how long it takes to create a measured drawing or map ${ }^{1}$. Once the photographer learns how many photographs are required to map a given subject, the entire photographic process becomes quite fast. And, the more sets of SfM photos a photographer takes, the better they become at planning out their photography route and taking into account lighting, vegetation, and camera settings. As presented in the below case studies, innovations in digital photography and aerial photographic systems allow SfM suitable photographs to be taken from virtually any platform, from the ground or suspended above the ground on a pole, kite, balloon, blimp, or unmanned aerial vehicles (e.g., Verhoeven 2009) (Figure 3). There

\footnotetext{
${ }^{1}$ Published sources are available describing different methods for collecting SfM photographs (e.g.,
} Douglass et al. 2015; De Reu et al. 2013; De Reu et al. 2014; Kjellman 2012). 
is no one-size-fits-all platform for collecting SfM photographs. The archeologist must take into consideration the size, shape, and desired resolution of the resulting 3D data in order to select the platform that will provide the best data. For instance, using a handheld camera is not the most effective way to photograph an entire drainage system, and unmanned aerial vehicles (UAVs) are not the best for photographing individual excavation units or profiles.

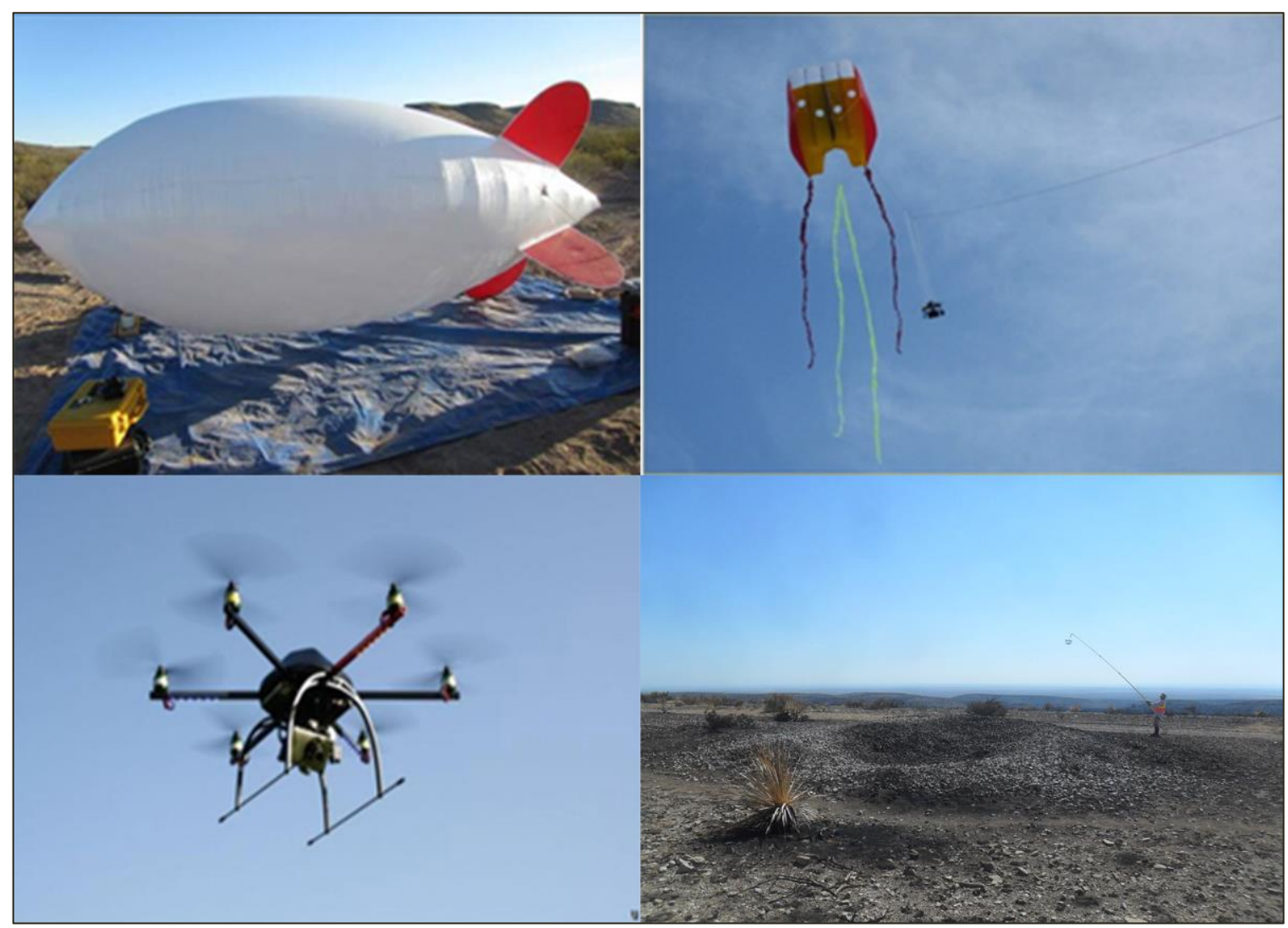

Figure 3. Different aerial platforms for collecting SfM photographs (from top left): Blimp, Kite, Pole, and UAV.

\section{Processing the Photographs using AgiSoft Photoscan}

Once a set of SfM photographs is collected, the images are loaded into a photo-processing software program such as Agisoft Photoscan ${ }^{2}$ (Verhoeven 2011). The basic principles when generating a 3D surface using SfM software is similar to traditional softcopy photogrammetry, but requires significantly less positional control and does not require a detailed calibration report for the camera used (Chandler 2005). Photoscan uses a scale-invariant feature transform (SIFT) algorithm to detect and match the locations of similar features in each image (Lowe 1999; see also McCarthy 2014). These similarities are then used to determine the basic shape of the subject and the vantage point each photograph was taken from. To dramatically increase the number of points in the resulting $3 \mathrm{D}$ model, a patch-based multi-view stereo (PMVS) algorithm is applied to the dataset (Furukawa and Ponce

${ }^{2}$ For our study we only use Agisoft Photoscan. There are additional software packages (for purchase and as freeware) available (e.g., Green et al. 2014). 
2007). This decomposes the input images into a set of image clusters of a manageable size for processing.

Within Photoscan, a 3D model is created by processing the data through several different steps (Figure 4). Agisoft Photoscan (Agisoft LLC 2014, 2015) offers a great advantage over other software packages because the programmers have made this series of seemingly complex steps possible in just a few mouse clicks ${ }^{3}$. The first step is aligning photographs, where points from each photograph are matched, and a sparse point cloud is generated (Figure 4a). From the sparse point cloud, a dense point cloud is generated (Figure $4 \mathrm{~b}$ ), which results in data points similar to data collected via laser scanning. After the point clouds are created, a 3D surface is generated by creating triangles between the thousands (or millions) of points (Figure 4c). Once the 3D surface is computed, a texture can be generated by creating a mosaic of all the photographs, which in turn can then be projected back onto the model to create a high-resolution, seamless image (Figure 4d). Once the 3D models are finished processing in Photoscan, the models themselves can be exported in a variety of $3 \mathrm{D}$ formats (e.g., OBJ, 3D PDF, PLY, and U3D). These exported files can then be viewed as fully textured 3D models in MeshLab or similar 3D viewing software (Figure 5). In addition, 2D digital elevation models (DEMs) and ortho imagery (e.g., De Reu et al. 2014) can be directly exported and virtually displayed, manipulated, measured, compared, or enhanced using GIS, Dstretch or other processing software (e.g., Adobe Photoshop).

\section{Ground Control Points}

SfM technology requires the use of Ground Control Points (GCPs) in order to georeference or position the photos (and subsequently, the SfM model) in real space (e.g., Douglass et al. 2015; De Rue et al. 2014; McCarthy 2014; Verhoeven et al. 2012). This is not to say 3D models without GCPs are useless, they will just lack scale and cardinal orientation. GCPs are simply points within the scene that have known coordinates. These coordinates can be real world values (like UTM or latitude and longitude, and elevation above mean sea level) or arbitrary such as an excavation-specific grid system. GCP points can range from temporary markers placed on the ground (e.g., paper plates or rocks inscribed with "X's") to excavation unit nails or other datums (Figure 6). The coordinates can be recorded with a TDS (e.g., De Reu et al. 2014:253; McCarthy 2014:Figure 3), GPS, or measured with tapes and line levels (e.g., Douglass et al. 2015:145). A method which will be discussed below is using a builder's square (e.g., Castañeda 2015; Nadel et al. 2015) to give a 3D model scale. The only critical requirement is that a minimum of three GCPs (several more are better, however) in each set of SfM photographs, and each GCP must be visible in multiple photographs. Once the $3 \mathrm{D}$ model is created in Photoscan, the user simply needs to find the GCPs in the photographs and digitally assign each GCP (Figure 7). After at least three GCPs are placed in the model, the defined coordinates for the GCPs are entered into Photoscan (Table 1), and the model is referenced to whatever coordinate system the GCPs are recorded within.

\footnotetext{
${ }^{3}$ Processing 3D models using AgiSoft Photoscan is explained in much greater detail by Douglass et al. (2015:141-143).
} 


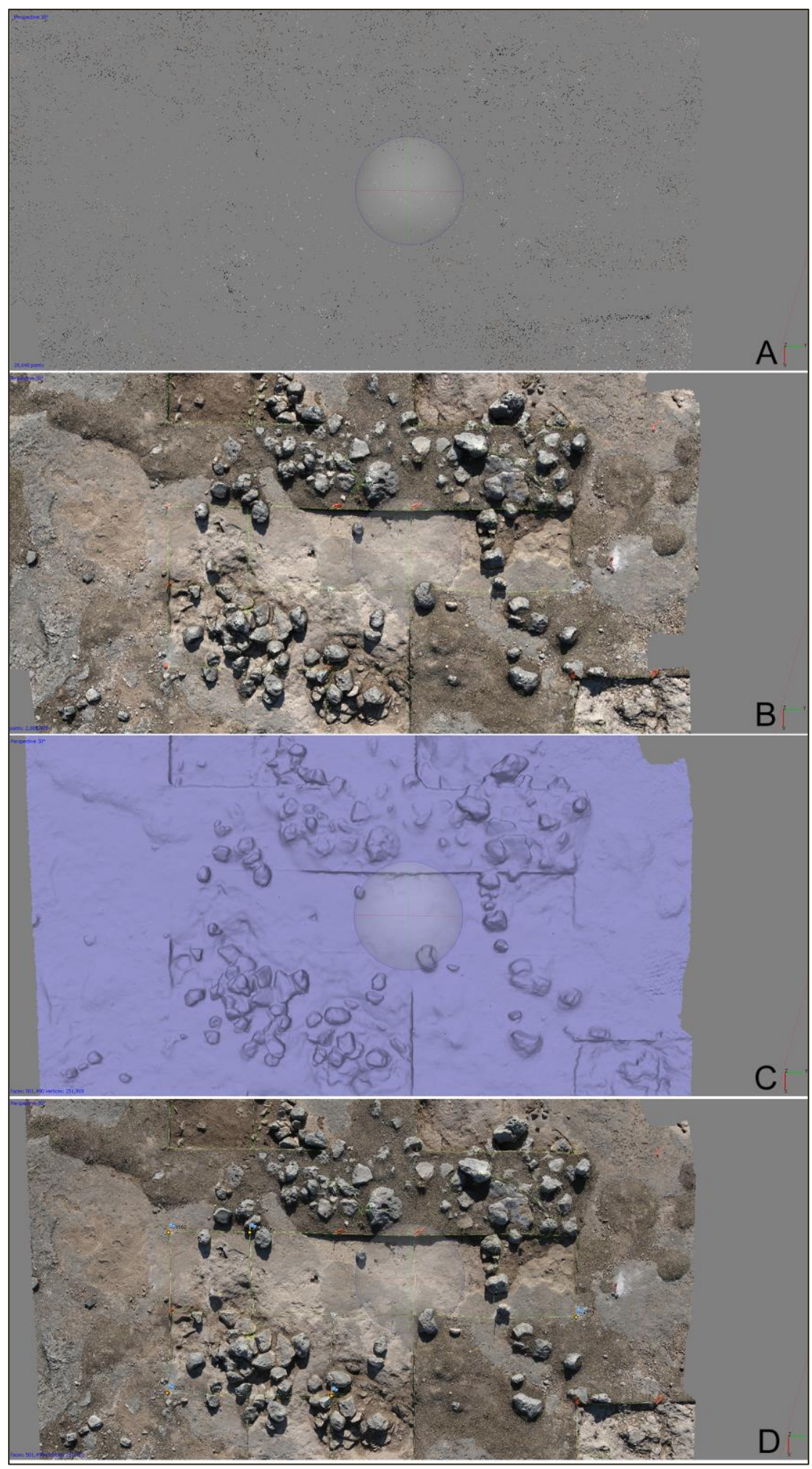

Figure 4. The central stone alignment at Javelina Heights shown at different points in the processing steps in AgiSoft Photoscan. From top to bottom: (a) sparse cloud, (b) dense cloud, (c) 3D mesh, and (d) photo-realistic texture. In the bottom image ground control points (blue flags) are also visible. 


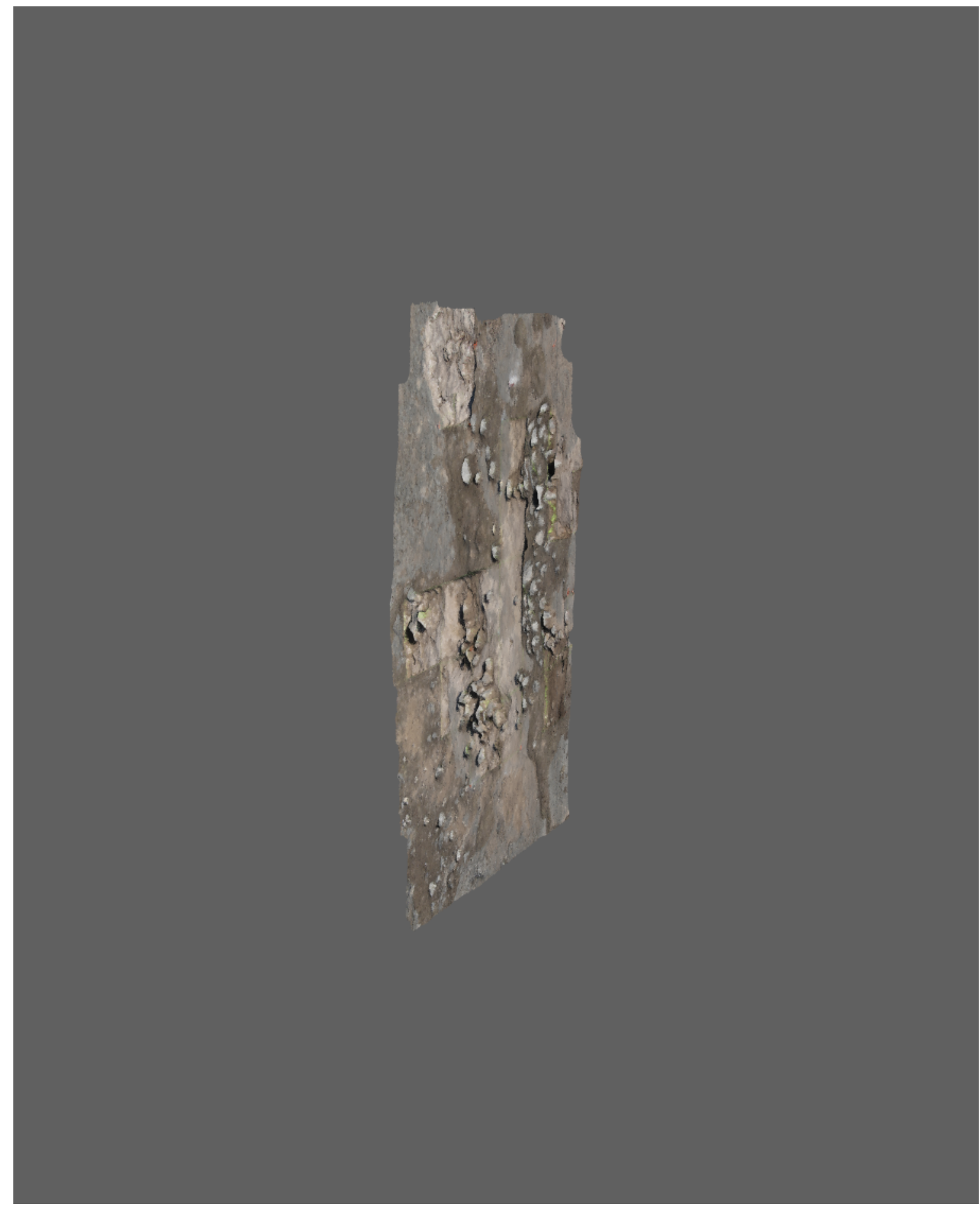

Figure 5. 3D model of the central stone alignment at Javelina Heights. This model can be measured, rotated, and otherwise manipulated by clicking image. Due to size constraints, the texture resolution is only $25 \%$ of the original. Click image to enable interactive content. 


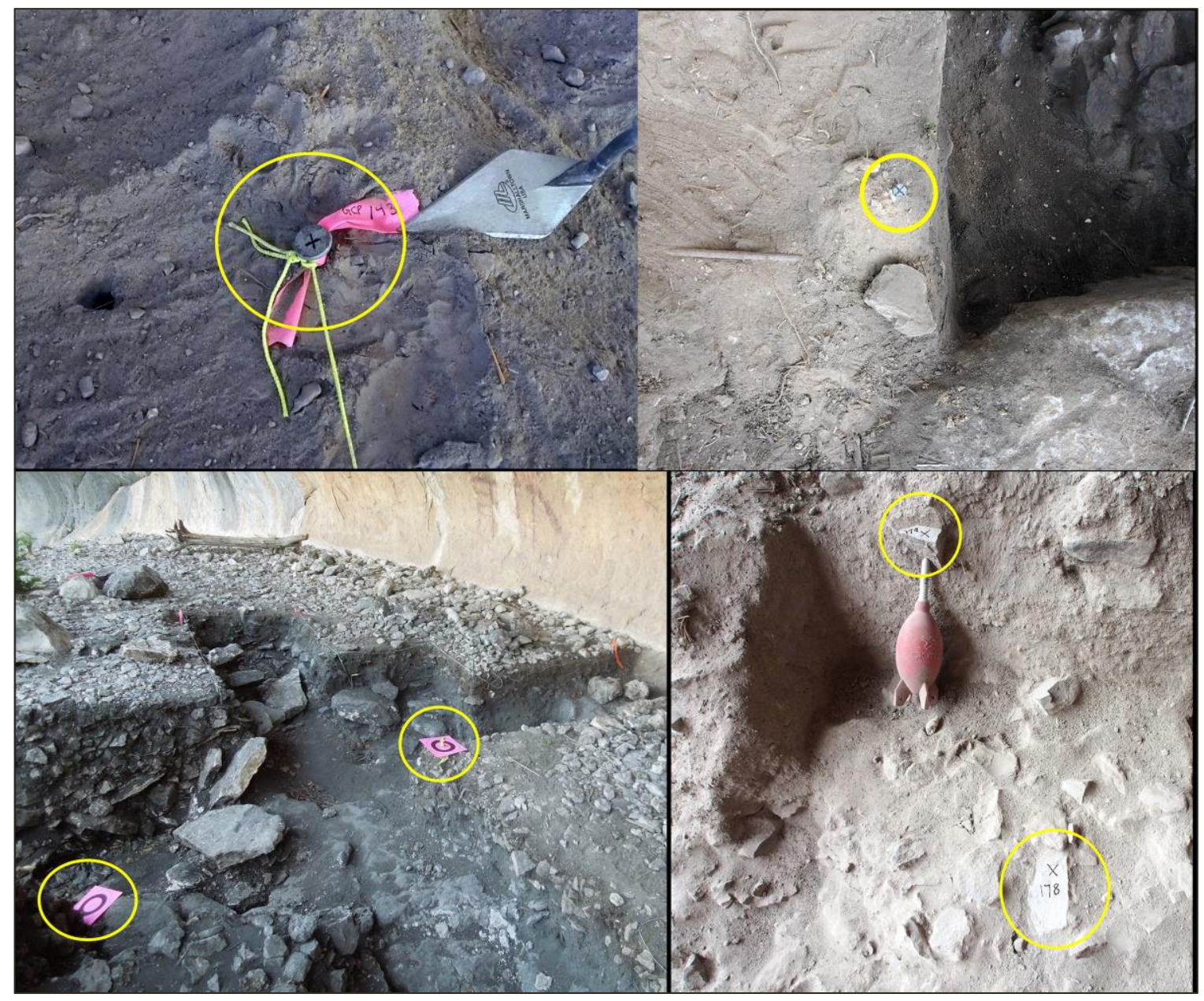

Figure 6. Exam ples of different GCPs in the field used to reference SfM 3D models. Clockwise from top right: excavation unitcorner, "X's" drawn on rocks, large pink paper targets, and a purposefully positioned nail with an "X" on nail head.

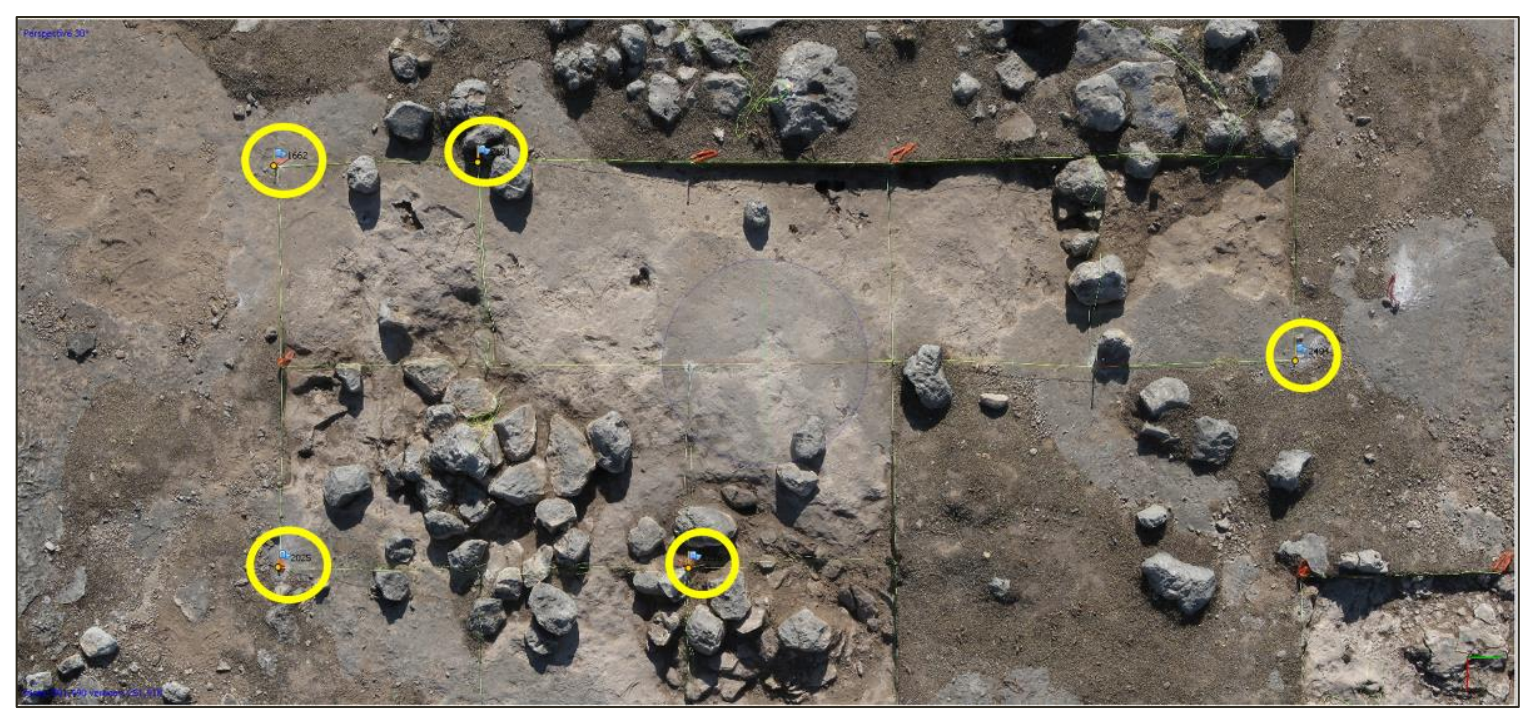

Figure 7. Exam ple of GCPs digitally placed onto the Javelina Heights 3D model in Photoscan. 
Table 1. Ground Control Points used to reference the Javelina Heights 3D Model

\begin{tabular}{lccccc}
\hline $\begin{array}{l}\text { Ground Control } \\
\text { Points }^{*}\end{array}$ & \multicolumn{3}{c}{ Values from TDS } & \multicolumn{2}{c}{ Calculated Error in Photoscan } \\
\cline { 2 - 6 } & $\mathbf{X}(\mathrm{m})$ & $\mathbf{Y}(\mathrm{m})$ & $\mathbf{Z}(\mathrm{m})$ & Error (mm) All GCPs & Error (mm) Selected GCPst \\
\hline GCP1216 & 995 & 995.001 & 99.967 & 9.9 & 3.8 \\
GCP1533 & 997.001 & 995.999 & 100.01 & 4.6 & 3.4 \\
GCP1662 & 993 & 993 & 99.994 & 21.2 & -- \\
GCP1670 & 991.002 & 997.001 & 99.975 & 27.9 & -- \\
GCP2025 & 995 & 993 & 100 & 36.1 & -- \\
GCP2101 & 993.001 & 994.001 & 99.94 & 53.7 & - \\
GCP2494 & 994 & 998.001 & 99.93 & 9.7 & 2.4 \\
Total Error & & & & 28.4 & 3.3
\end{tabular}

${ }^{*}$ All GCPS are unitcorners shot in with a TDS

tSelecting different combinations of GCPs will decrease the total error across a given 3D model

${ }^{\wedge}$ Error values are RMS values

\section{CASE EXAMPLES}

In the past several years we have used SfM methods and processing software to document a variety of open and sheltered hunter-gatherer sites and site features including individual earth ovens (e.g., Basham 2015; Campbell 2012), bedrock grinding features (e.g., Castañeda 2015), large plantbaking facilities (burned rock middens) (e.g., Graves et al. 2013; Koenig 2012; Roberts and Alvarado 2011), and rock art panels (e.g., Kenmotsu et al. 2012). The case examples presented here are all from the semiarid landscapes of southwestern Texas and southeastern New Mexico. Willis and others have applied the same technology in many other archeological contexts across the globe, from tropical jungles (e.g., Willis et al. 2014) to Andean meadows (e.g., Athens et al. 2015) to deciduous forests (e.g., Magnani and Schroder 2015) to underwater sites (e.g., Drap 2012). In the examples discussed below, the subjects range in scale from landscape to sub-centimeter level, and are intended to demonstrate the different ways SfM photographs are collected to address specific archeological problems. We begin with landscape data collected from aerial platforms.

\section{UAV}

Unmanned Aerial Vehicles (UAVs), sometimes called drones, are new to archeological reconnaissance and are the fastest way to produce high resolution 3D models of entire landscapes (e.g., Liebman et al. 2013; Lin et al. 2011; Willis 2013). These camera-equipped machines range from light-weight fixed-wing aircraft made of foam, to heavier multi-bladed helicopters. UAVs differ from remote controlled devices in that they are autonomous robotic machines that navigate a pre-defined flight plan using an onboard GPS by making internal, split-second decisions ${ }^{4}$. This makes UAVs

\footnotetext{
${ }^{4}$ If a UAV navigates with an onboard GPS, GCPs are not always necessary. However, we generally have GCPs visible in the SfM sets to ensure the resulting 3D models can be referenced. This is especially true if the UAV data is referenced to UTM or latitude/longitude, but the area/site being photographed is documented using a local grid system.
} 
extremely efficient for systematically documenting large areas. Data are typically collected from heights ranging from 35 meters above the ground to well over 100 meters. The closer the UAV is to the ground, the higher the resolution of the photographs. The lowest altitude flights (ca. 30-40 m) collect photographs with a ground resolution of about $2 \mathrm{~cm}$-in other words, every $2 \mathrm{~cm}$ on the ground is associated with a pixel in a photograph. Depending on the resolution required, the UAV can document dozens of square kilometers a day.

A foam "flying wing" style UAV was used to document the landscape in and around the Rancid Cactus site, 41VV2053 (Figure 8). The flying wing UAV weighs several ounces and is launched by throwing it into the air and then it self-navigates using an onboard GPS and autopilot (see Willis 2013). Rancid Cactus is a small burned rock midden (BRM) located on an upland ridge in the Lower Pecos Canyonlands of southwest Texas (Koenig 2012:78-79, 285-289). Small BRMs are often subtle features on the landscape, marked mainly by a dense, low-relief concentration of fire-cracked rock (FCR) that blends in with the native limestone bedrock. In other words, Rancid Cactus is not a visually or topographically impressive site. Prior to UAV mapping, the highest resolution digital elevation model (DEM) available for the site area was 10 meters, which did not provide near enough detail to assist in finding additional features or even accurately map the site. The UAV flew 70 transects across the area of interest in approximately two hours. This generated 2000 photographs covering a four square kilometer area with a ground resolution of $4 \mathrm{~cm}$, adequate to identify burned rock features in the landscape and produce a high quality site map.

\section{KAP and BAP}

Kite Aerial Photography (KAP) and Balloon Aerial Photography (BAP) have been in use for over a century (Brandon 2012). Kites, of course, are best suited for windy conditions, while balloons require relatively calm conditions. Both are inexpensive methods for getting a camera in the air (Reinhard 2012; Verhoeven 2009, 2011; Verhoeven et al. 2012). Unlike UAVs, KAP/BAP can collect photographs from a greater range of altitudes. KAP/BAP can be flown from as low as a few meters off the ground to well over 200 meters (Figure 9). Systematically collecting data via these platforms can be difficult because of changing wind conditions and the fact that while flying the kite or blimp the operator cannot know exactly where the camera is aimed. Nonetheless, with experience the method can produce sub-centimeter resolution SfM models, and is suited for any budget. GCPs are required to reference $\mathrm{KAP} / \mathrm{BAP}$ data.

In May 2005, Willis used KAP to map Madera Quemada, a Jornada Mogollon pueblo site located in southeastern New Mexico (Figure 10). At that time he was using traditional photogrammetry techniques to create $3 \mathrm{D}$ models of archeological sites. The project involved flying a KAP rig in a series of transects ranging from 5 to 40 meters above excavations of the nearly fully exposed room block. In 2005, the data was processed using an expensive software package called Leica Photogrammetry Suite ${ }^{\mathrm{TM}}$. The quality of the original models was satisfactory, but several years later Willis reprocessed the imagery when Agisoft Photoscan became available and created a much higher resolution model. This low-cost work provided an extremely high resolution photogrammetric 


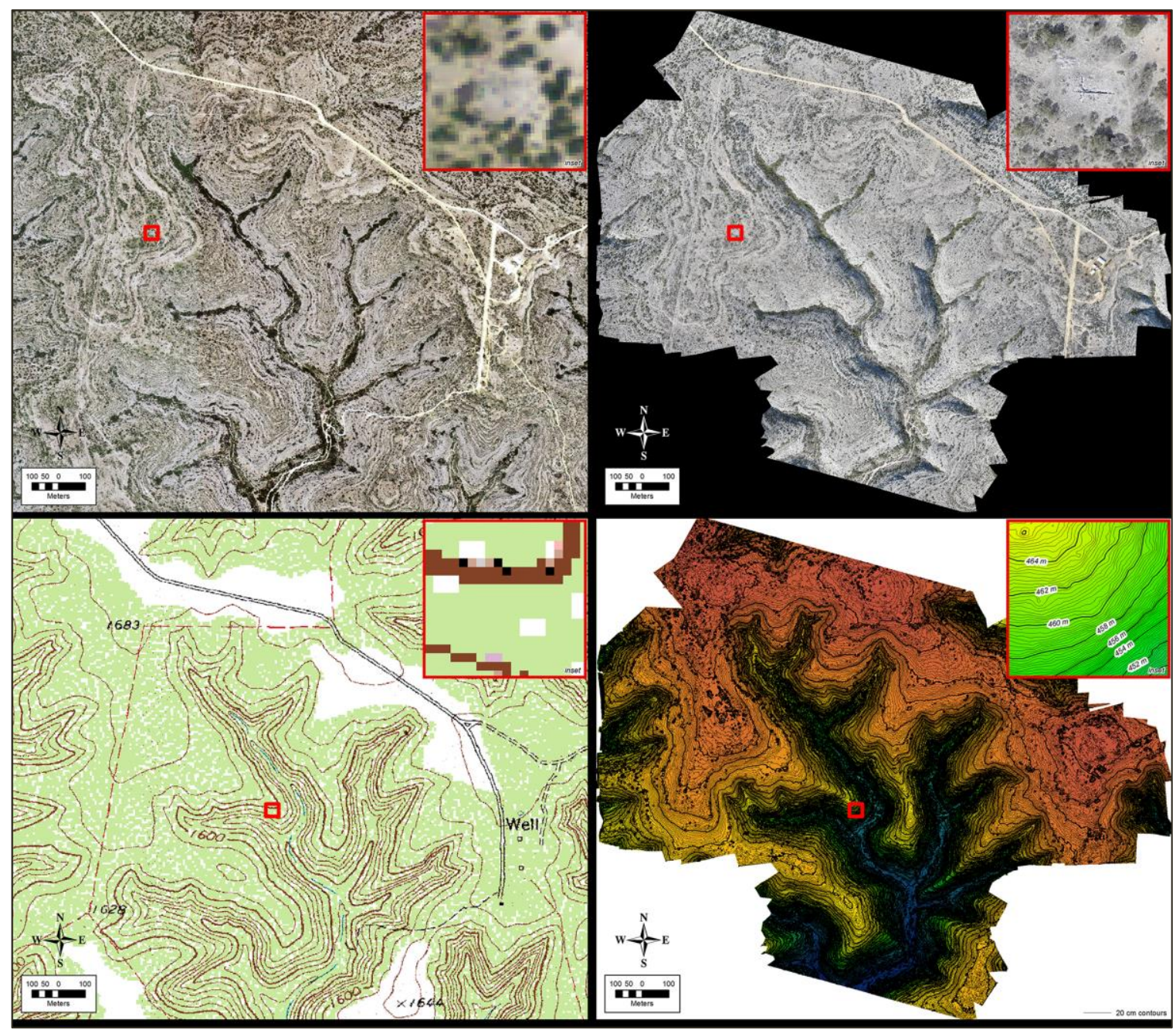

Figure 8. A UAV was flown over the area surrounding Rancid Cactus (41VV2053). The USGS ortho-image (top left) and contour map (bottom left) had 10 meter resolution. Flying only for 2 hours, the UAV was able to photograph the area and produce ortho imagery (top right) and DEM/contour lines (bottom right) with better than 5 centimeter resolution.

model of the site's core and revealed details of the site's morphology, such as hard-to-see subfloor pits and wall abutments, which were not apparent from ground level (Miller and Graves 2009). Furthermore, this example shows the usefulness of reprocessing photographic data collected prior to the advent of SfM.

\section{PAP}

Another very cost-effective method for producing SfM models is Pole Aerial Photography (PAP). Like KAP, this method has been used at archeological sites for decades, but with the rise of SfM it has much more utility (Campbell 2012; De Reu et al. 2014; Houk 2013; Verhoeven 2009). As the name suggests, this technique involves attaching a camera to a long pole to take photographs from very low altitude $(3-5 \mathrm{~m})$. The pole most often used today is a telescoping extension pole found at hardware 

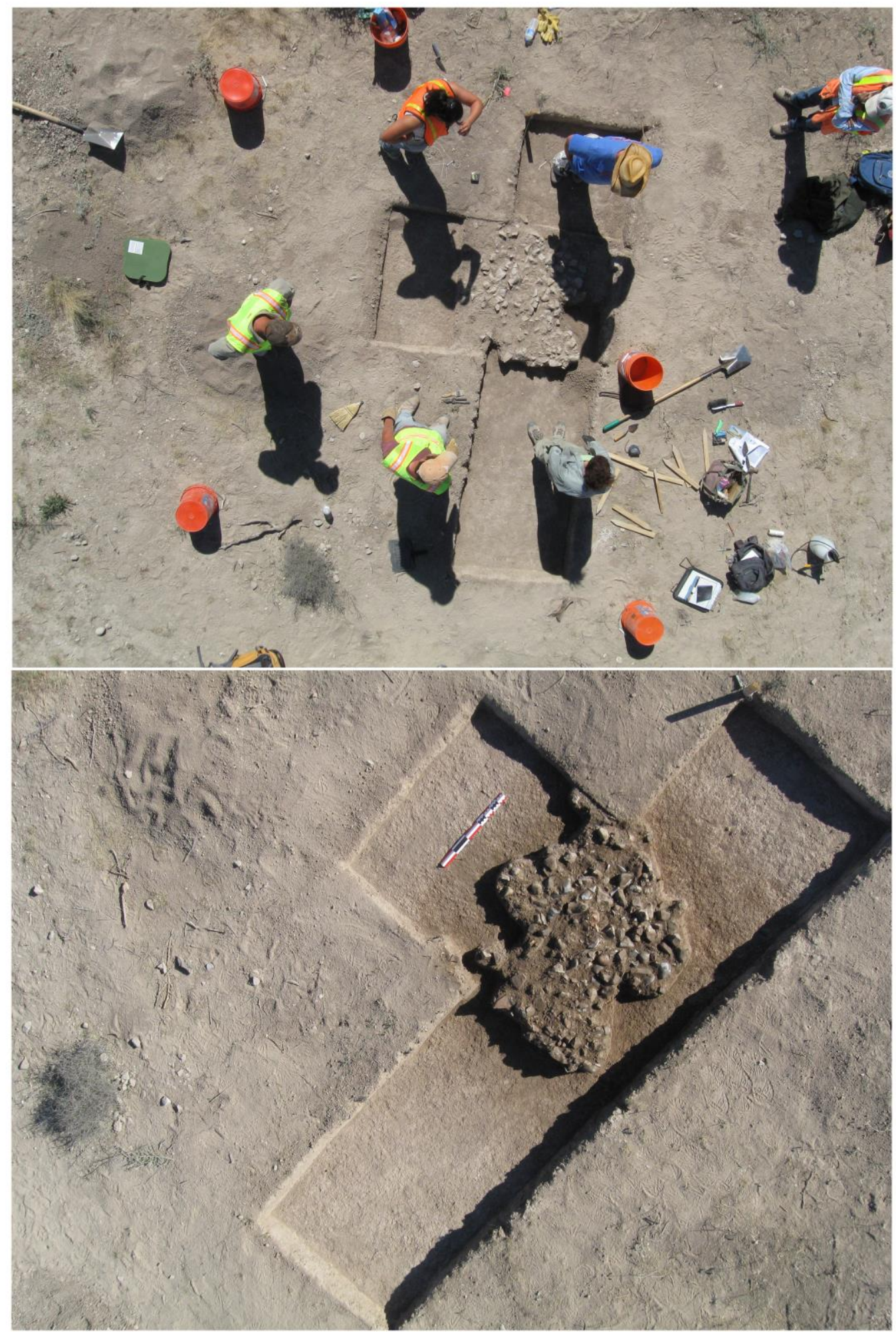

Figure 9. Aerial photographs of archaeological work taken with KAP. Overview of excavation in progress (top), and the feature fully exposed (bottom). KAP and other aerial platforms do notonly provide excellent spatial data, but they also take work photographs from unique perspectives. 

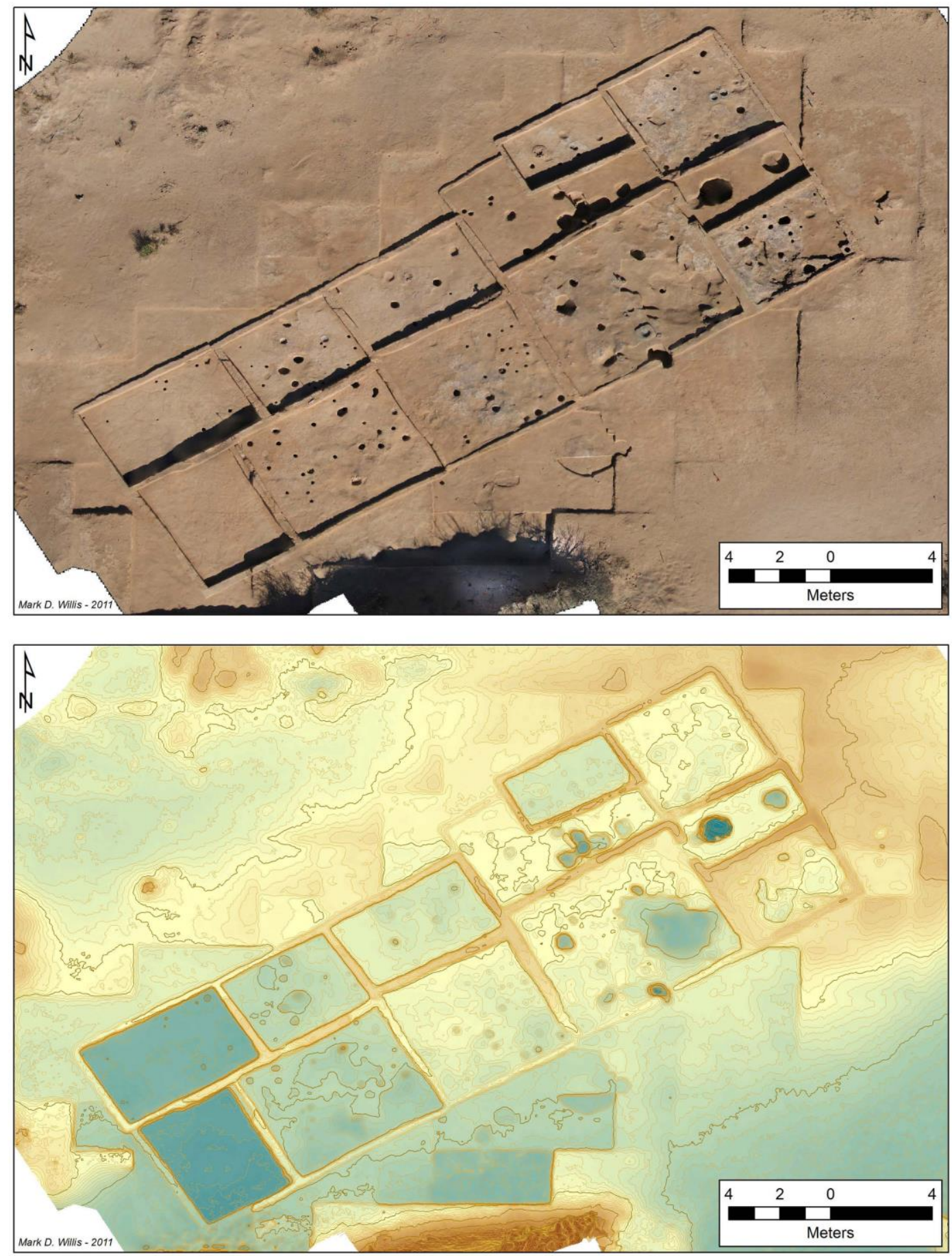

Figure 10. An orthophoto (4a) and DEM/contour map (4b) of Madera Quemada pueblo (LA 91220) created using photographs taken from a kite.

stores. For archeological documentation of relatively small areas, the camera pole is held out from the photographer at about a 45 degree angle, and overlapping photographs are taken at even intervals as transects are walked. As is the case with most of the other techniques, GCPs are required to be able to 
georeference the data. Although PAP is very efficient for documenting discrete areas, Willis used the technique to map a 20-acre petroglyph site in southwest Texas (see Manaugh 2013).

The PAP technique was used to good result on burned rock midden feature at the Guadalupe Ridge Site in Southeastern New Mexico after a fortuitous wildfire had exposed features previously hidden by vegetation (Figure 11). After clearing away some of the burned plants from the feature, the PAP rig was slowly walked across the feature in a series of ten transects. A $10-\mathrm{x}-10 \mathrm{~m}$ area was photographed in this fashion and 158 photographs were processed using SfM and high-resolution GIS data was generated. The resulting orthophoto has a resolution of $1 \mathrm{~mm} /$ pixel, and contours at $1 \mathrm{~cm}$ intervals were generated from the DEM. Individual rocks are clearly visible in the imagery and analysis of the DEM revealed subtle depressions in the feature that were not otherwise apparent (Graves et al. 2013; Willis 2010).

\section{Ground-Based}

One of the most revolutionary aspects of SfM documentation is that in many circumstances only a hand-held camera is needed to produce excellent data. A distinct advantage of this approach is that much heavier and higher quality cameras can be used, as the other techniques lend themselves to the lightest cameras possible. Ground-based SfM allows for the documentation of vertical surfaces and can produce sub-millimeter resolution ortho-imagery and DEMs (Figure 12). Since the camera is usually very close to the subject matter, this technique is well suited to documenting relatively small areas, such as excavation units or features less than twenty meters in size. We have, however, also used this technique to document large sites (Figure 13) and large vertical exposures (Figure 14).

\section{Layer by Layer Excavation Using SfM}

Currently, Koenig and Black are using ground-based SfM as the primary documentation method to precisely document excavation units and stratigraphic exposures at several dry rockshelters in the Lower Pecos Canyonlands (Koenig et al. 2016.; Rodriguez 2015; see http://aswtproject.wordpress.com/ ). Our methods for documenting excavation units and profiles using SfM furthers the work presented by De Reu et al. (2014). For each new horizontal and vertical exposure, a set of SfM photographs is taken using hand-held digital cameras (Figure 15), making certain at least six GCPs (three being the minimum) are visible within each overlapping set. Each GCP is shot in with a TDS, and most GCPs are used in multiple SfM sets as excavations continue. The ground-based approach allows us to eschew arbitrary metric excavation and use stratigraphic excavation methods and pragmatic units of any configuration. Arbitrary square-hole methods are often perceived as necessary to be able to maintain accurate provenience, but with SfM everything included in the photograph is then referenced by the GCPs no matter the size, shape, or orientation of an excavated layer. And, because the 3D models are referenced to a coordinate system, one can easily calculate unit layer volumes and artifact density from the SfM data (Table 2). 

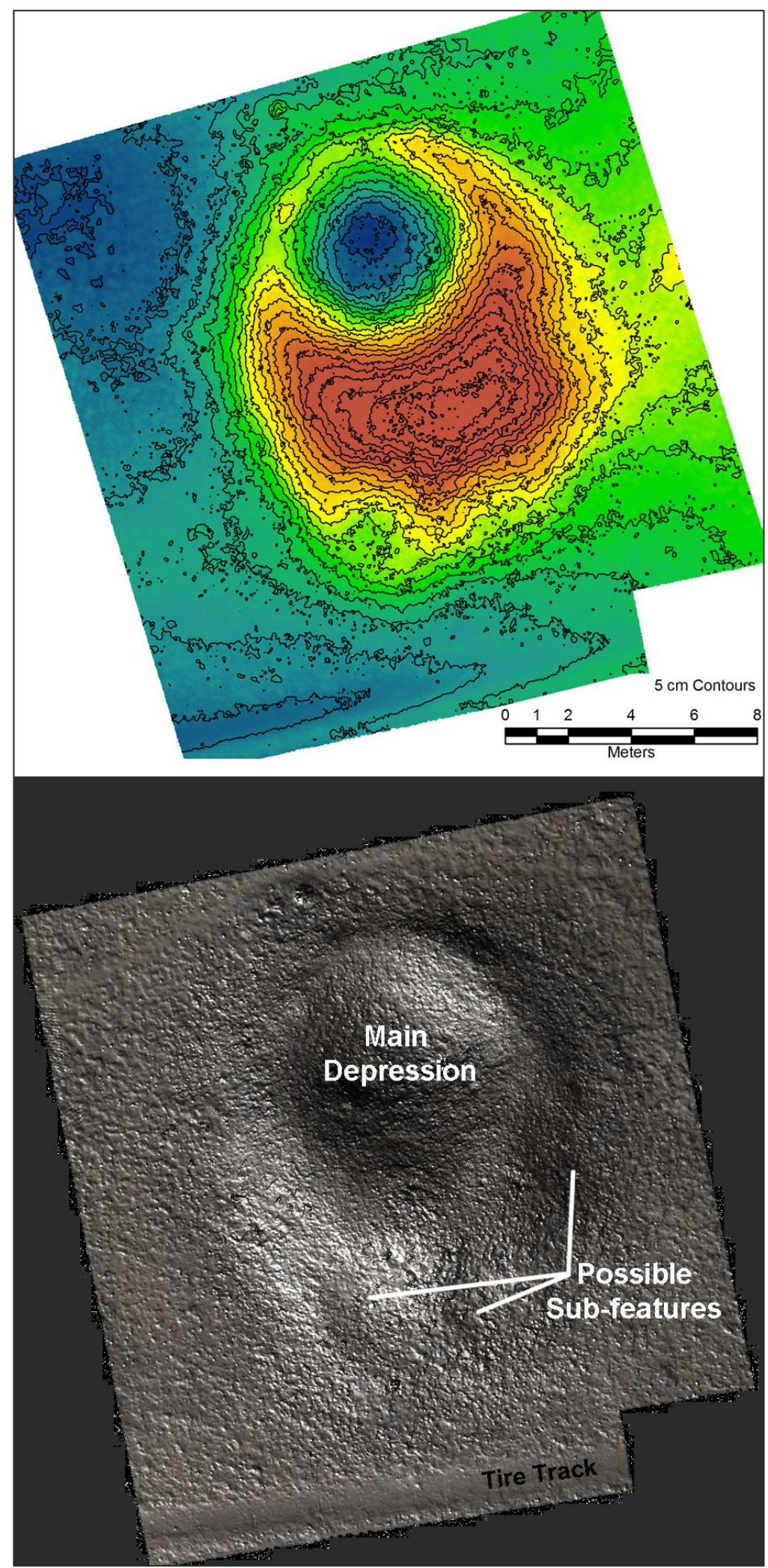

Figure 11. The Guadalupe Village burned rock midden (LA 143472) was photographed using a PAP setup. The resulting DEM and slope models in GIS showed details that were not otherwise observed on site. 


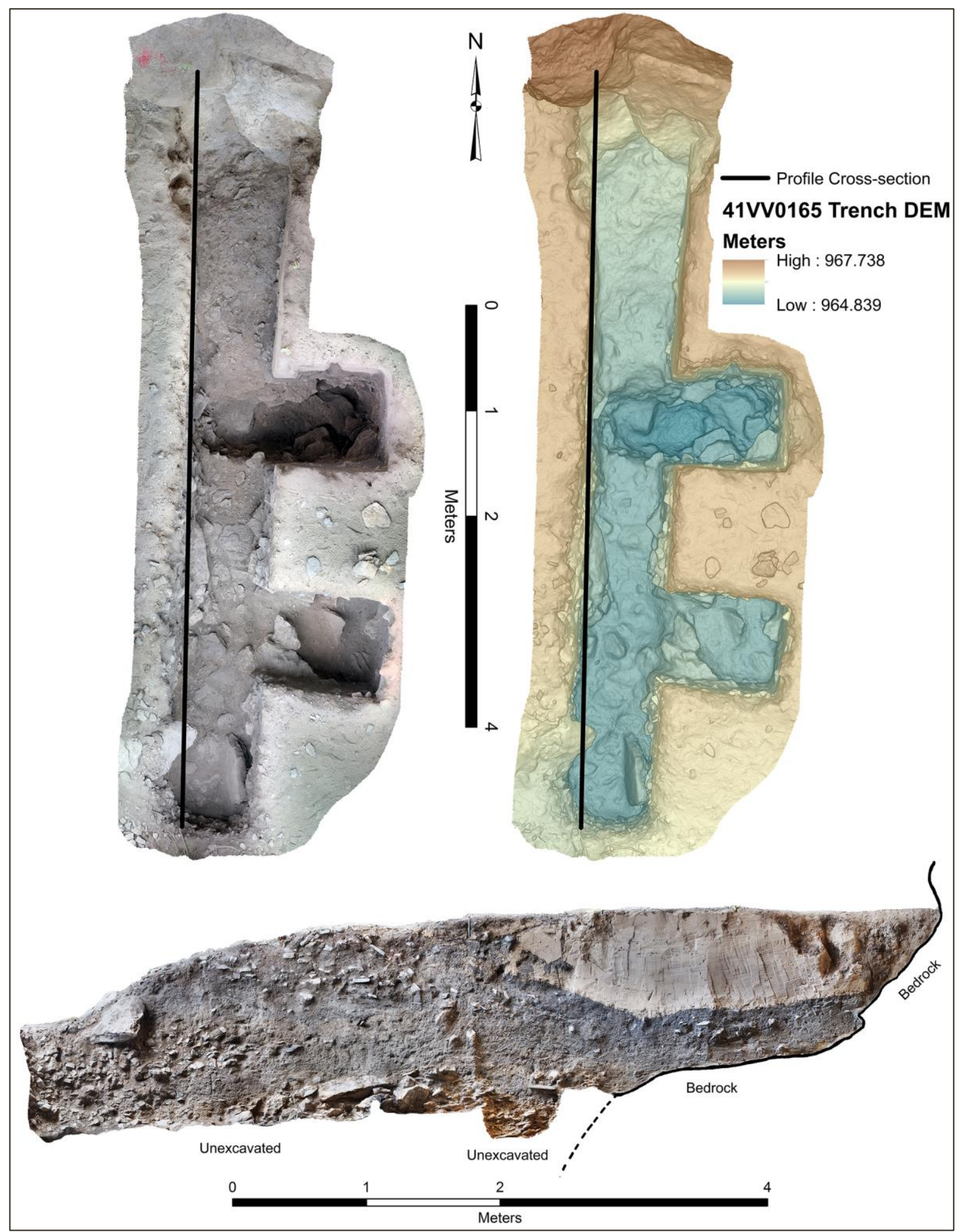

Figure 12. 3D surfaces of the main excavation trench at Skiles Shelter (41VV165) created using ground-based SfM. The main trench (top) was modeled with 250 photographs, and the DEM (top right) was exported with a pixel resolution of $1 \mathrm{~mm}$ and the orthographic image (top left) exported with $.5 \mathrm{~mm}$ resolution. The trench profile (bottom) was generated from 750 photographs, and the orthophoto exported with $.2 \mathrm{~mm}$ pixel resolution. 


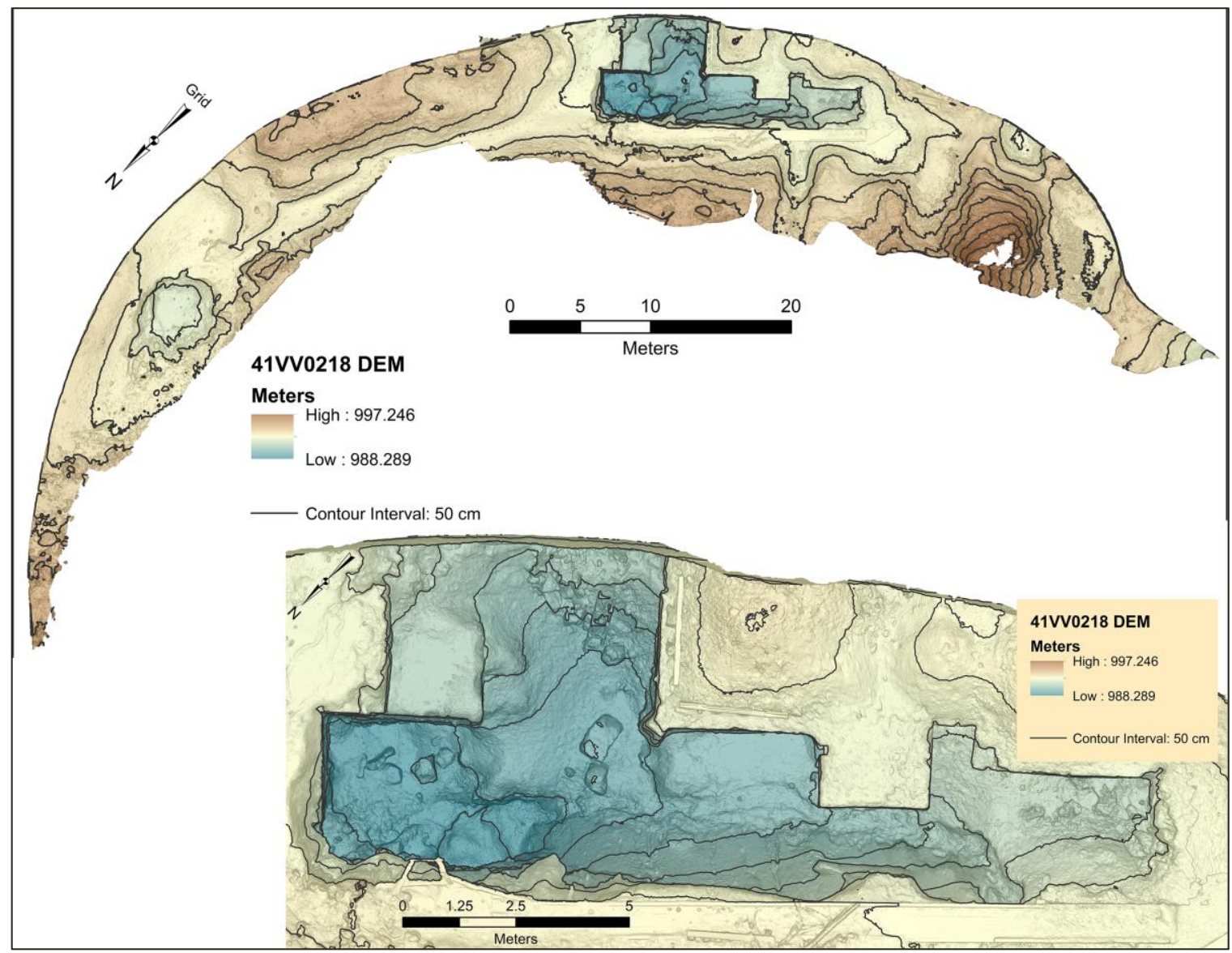

Figure 13. The interior of Bonfire Shelter (41VV218) was mapped using ground-based SfM in fall of 2014. The 3D model was generated from 3500 photographs, and the orthophoto has a pixel resolution of $1 \mathrm{~mm}$, and the DEM has a $3 \mathrm{~cm}$ pixel resolution. The contour interval is $50 \mathrm{~cm}$.

Another great advantage of using SfM as a primary documentation method is the rapid turnaround. Typically, each evening we download the SfM images taken during the field day, use Photoscan to create 3D models, and the next morning return to the field site armed with color inkjet orthophotos of the excavation unit, feature, or profile in question. We are then able to annotate the images, noting subtle stratigraphic interfaces, sample locations, and various other data without the time consuming process of producing measured hand-drawn documents. Admittedly we have the great advantage of having a nearby digital field laboratory with several workstations including a powerful desktop computer for rapid image processing and a color printer. Willis, however, has achieved similar results in a motel room armed only with a decent laptop and access to a printer.

A final advantage to the routine use of hand-held cameras for daily SfM photo documentation is that, as De Reu et al. (2013) point out, this creates a digital record of the archeological excavation sequence that will be available for future researchers (Figure 16). With multiple sets of SfM documentation of the same excavation area, one can later watch and re-watch successive excavated surfaces come to light. 


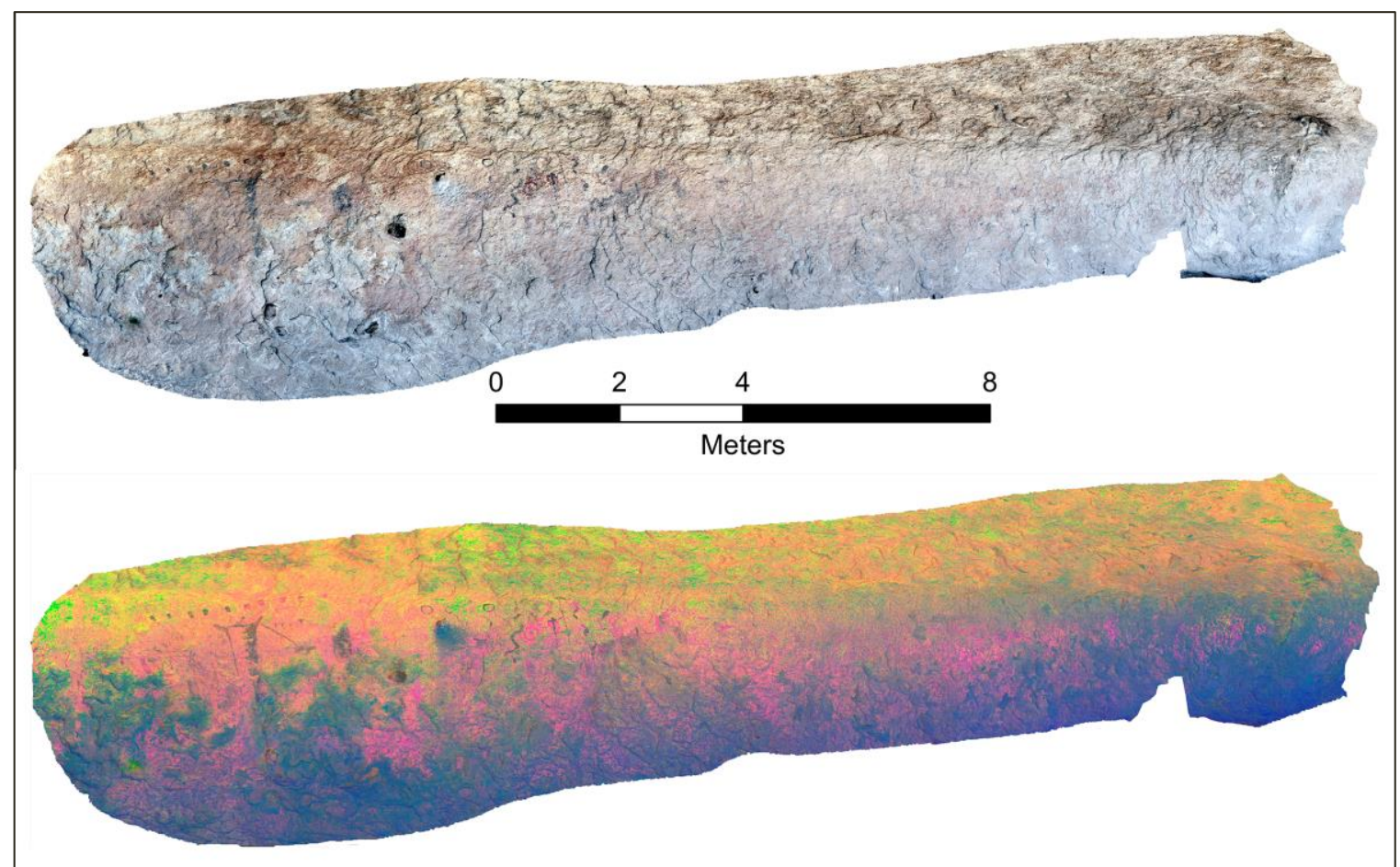

Figure 14. The main pictograph panel at Eagle Cave (41W167) was mapped using ground-based SfM. The 3D model was generated from 400 photographs, and the orthophoto has a pixel resolution of $2 \mathrm{~mm}$. The full-color orthophoto (top) was loaded into D-Stretch (bottom) to bring out more details of the pictographs. Image courtesy Shumla Archaeological Research and Education Center.

Table 2. Cut Fill volume calculation for UnitIL, Layers 4-8 from Horse Trail Shelter with calculated FCR density.

\begin{tabular}{|c|c|c|c|c|}
\hline \multirow{2}{*}{ Layer Sampled } & \multicolumn{2}{|c|}{ Cut-Fill Volume calculation } & \multirow{2}{*}{ FCR Mass (kg) } & \multirow{2}{*}{$\begin{array}{l}\text { FCR Density } \\
\quad\left(\mathrm{kg} / \mathrm{m}^{3}\right)\end{array}$} \\
\hline & $\mathrm{m}^{3}$ & $\mathbf{L}$ & & \\
\hline Layer 4 & 0.0453 & 45.3 & 1.59 & 35.10 \\
\hline Layer 5 & 0.0057 & 5.7 & 2.02 & 354.39 \\
\hline Layer $6^{*}$ & 0.0191 & 19.1 & 14.09 & 737.70 \\
\hline Layer $7^{*}$ & 0.0192 & 19.2 & 14.32 & 745.83 \\
\hline Layer 8 & 0.0330 & 33 & 3.68 & 111.52 \\
\hline
\end{tabular}

*Layers 6 and 7 appeared to be a largely intactheating element 


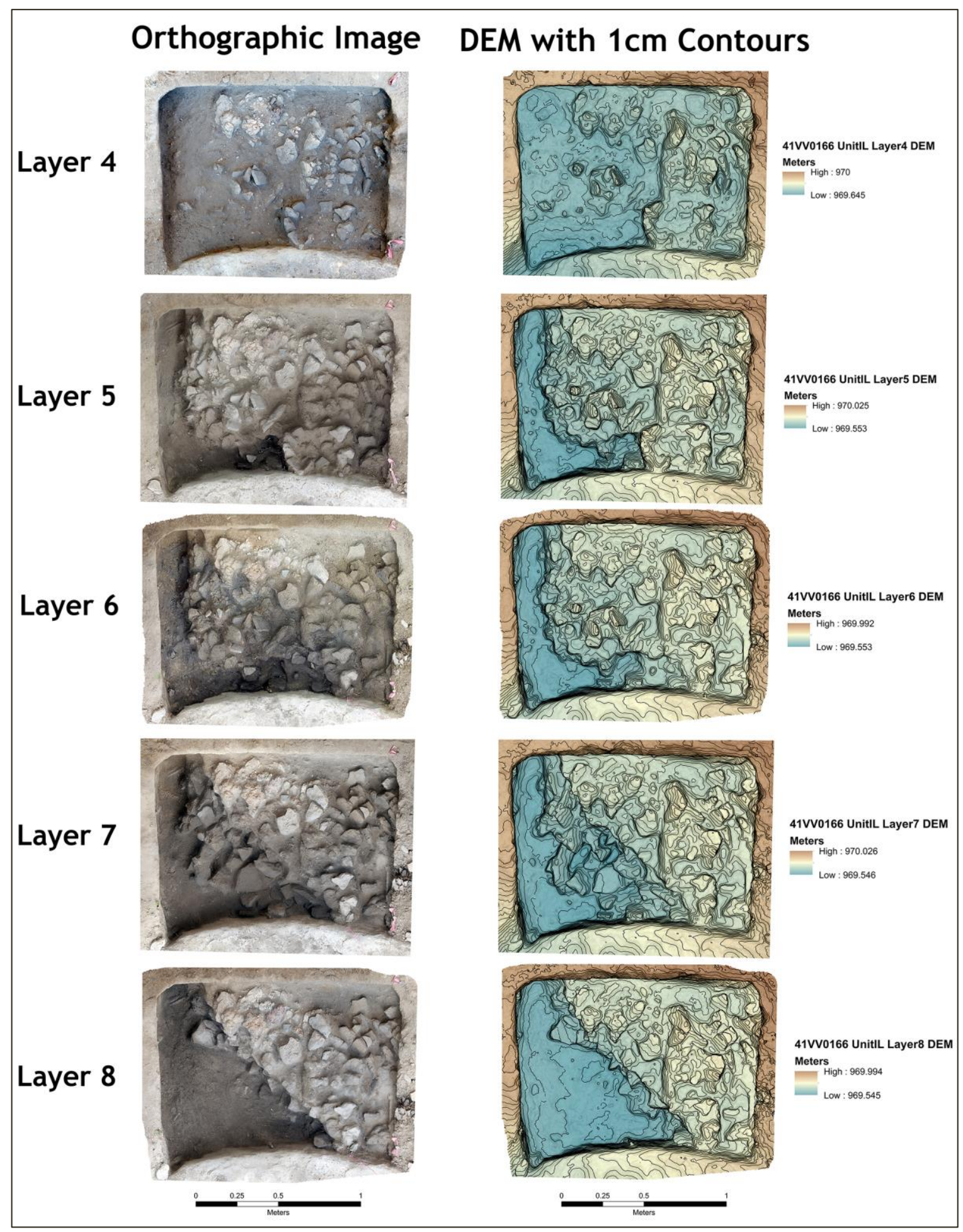

Figure 15. Layer by layer SfM excavation of Unit IL, Layers 4-8 from Horse Trail Shelter (41W166). Each image shows the upper surfaces of the excavated layers. The images on the left are orthophotos exported with resolution of $5 \mathrm{~mm}$, and the DEMs on the right exported with $1 \mathrm{~mm}$ resolution with $5 \mathrm{~mm}$ contour lines overlaid. These DEMs can be easily used to calculate excavated volumes in GIS using the Cut Fill tool. 


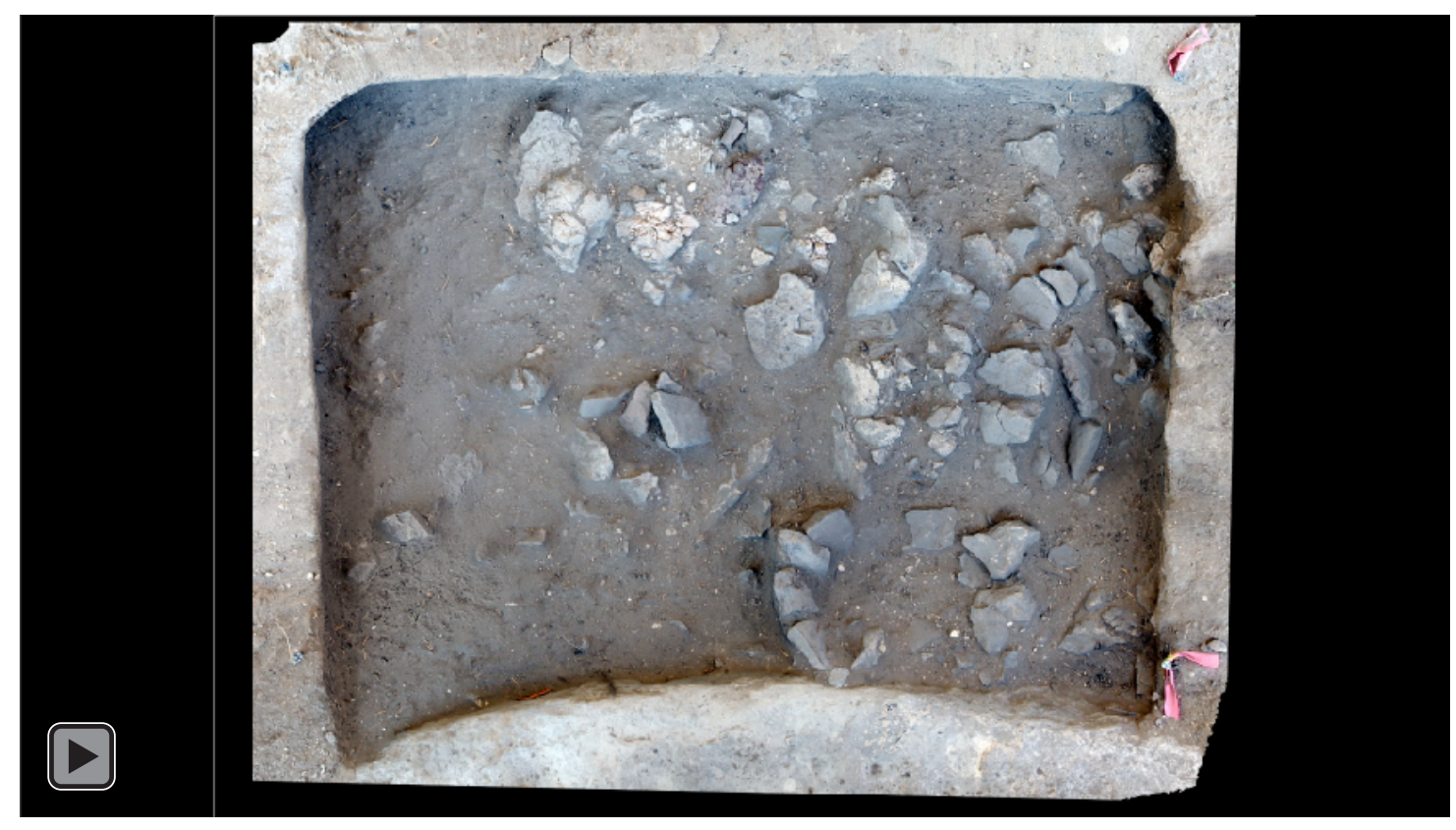

Figure 16. Animation showing the excavation of Unit IL, Layers 4-12 from Horse Trail Shelter (41VV166). Clickimage to enable playback. 


\section{Using Ground-based SfM for Documenting Bedrock Features}

$\mathrm{SfM}$ is also being used for documenting permanent and semi-portable ground stone bedrock features in various regions (e.g., Castañeda 2015; Dreyer-Lynch 2014; Nadel et al. 2015). However, unlike recording excavation units, documenting bedrock features is usually done on the fly and without the presence of a TDS for establishing GCPs. In order to establish a reference system for bedrock features recorded at different sites without the use of a TDS, Castañeda (2015) used a builder's square (also called an "L" or right angle ruler) (Figure 17). Although a builder's square cannot georeference a model to UTM, Latitude/Longitude, or local grid coordinates, it can still be used to internally reference each of the 3D models with appropriate scale (meters, centimeters, etc.) and orientation (up, down, cardinal direction) (Figure 18).

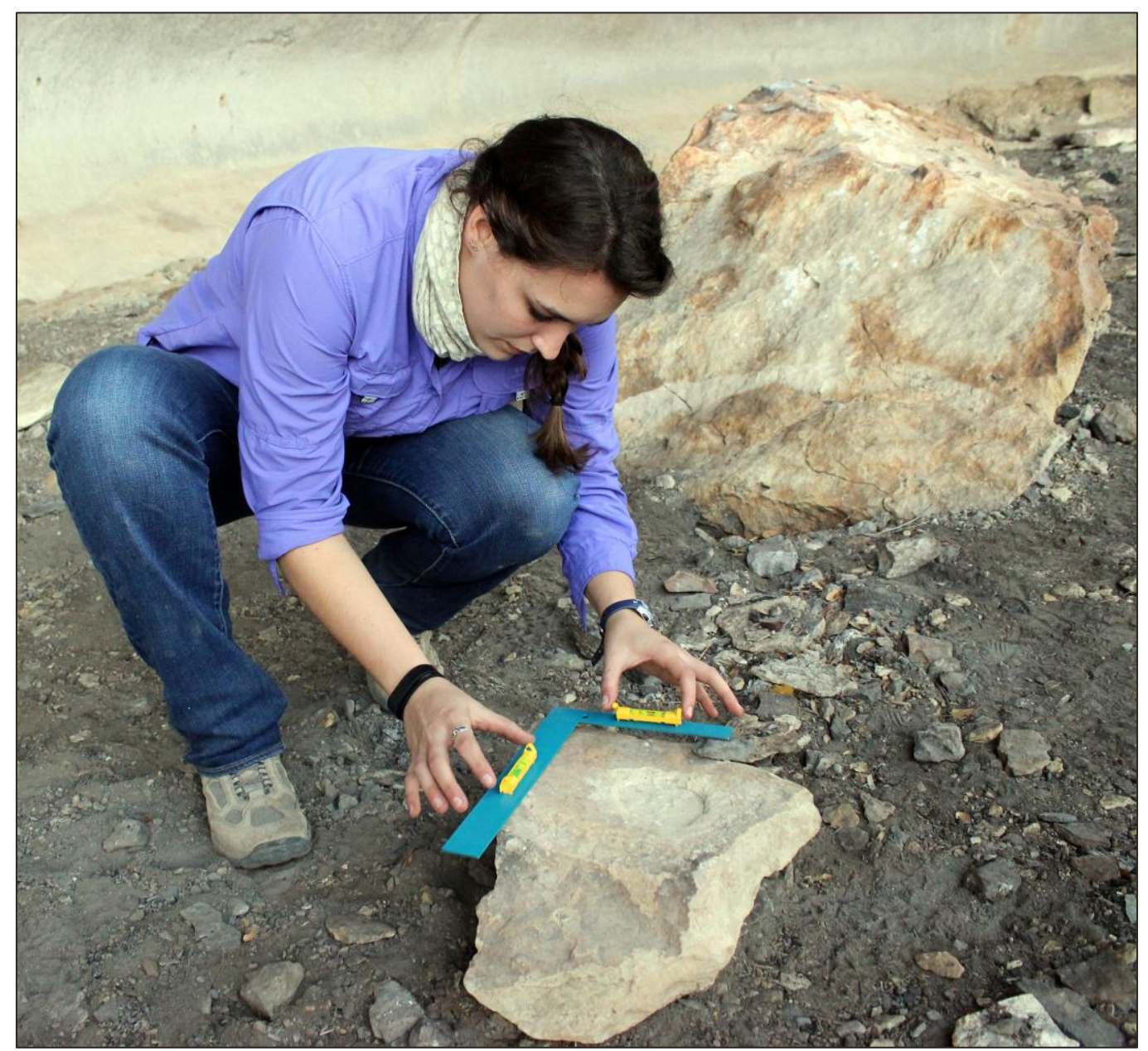

Figure 17. Amanda Castañeda using a Builder's Square to establish a reference grid for a portable grinding slab. The levels are used to be sure the builder's square is level across the entire surface. 


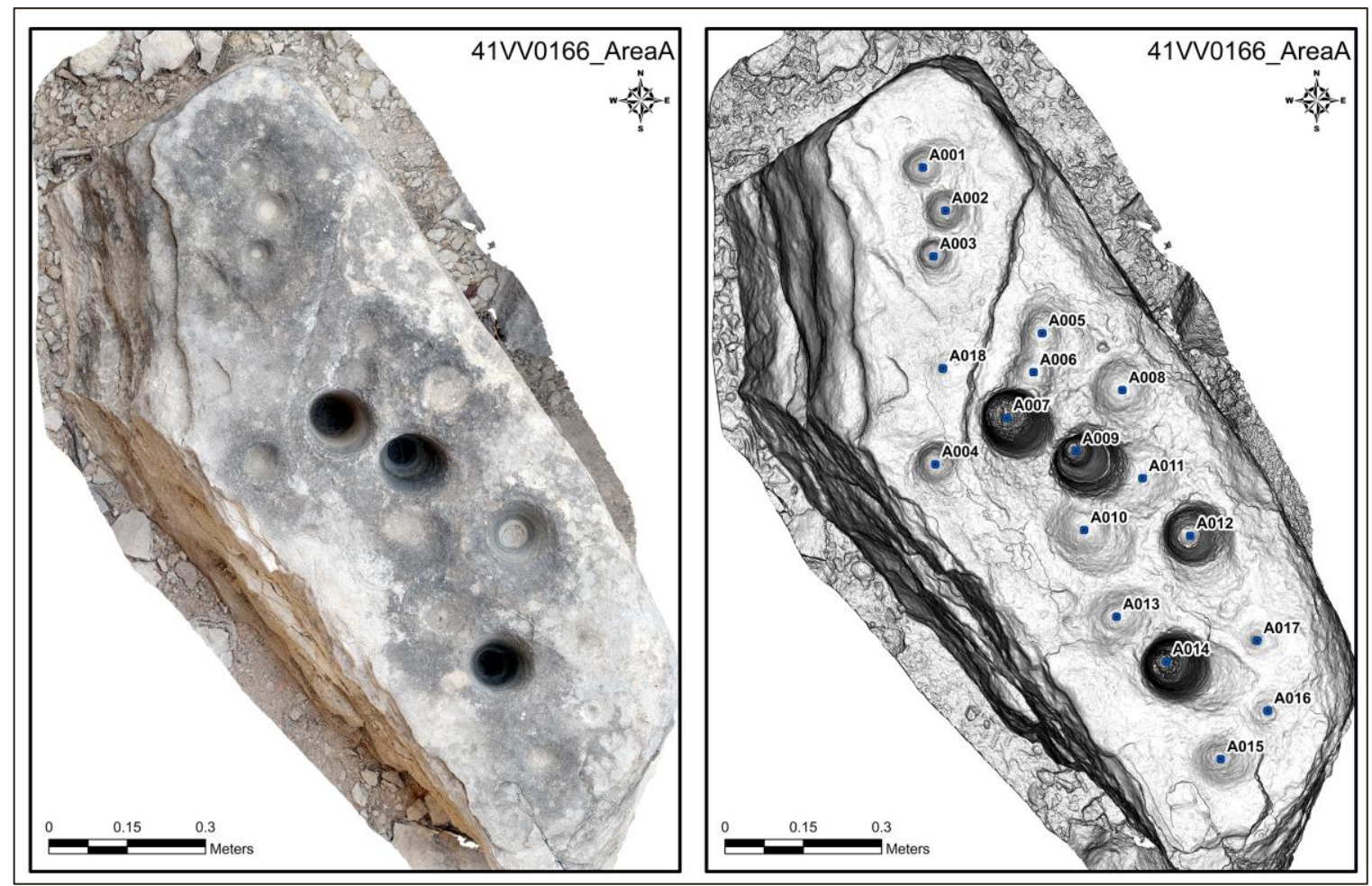

Figure 18. A bedrock feature from Horse Trail Shelter (41VV166) referenced using a builder's square. Orthographic image (left) and slope model generated from a DEM (right) exported from Photoscan.

When using a right-angle ruler to create GCPs for a SfM model, the ruler must be set up adjacent to the targeted area and then photographed. The horizontal and vertical "arms" of the ruler serve as $\mathrm{X}$ and $\mathrm{Y}$ axes. In order to add the third dimension (elevation), bubble levels are used to level each arm of the ruler so the entire builder's square has the same elevation (see Figure 17). Rocks or other small items can be placed under the arms to level the ruler. After the ruler has been photographed, it can be taken away and the subject can be photographed as normal. Because the ruler has markings in a known scale, once the 3D model is finished processing in Photoscan GCPs can be digitally placed directly onto the ruler to reference the model (Figure 19, Table 3). Using the right-angle ruler method provides the ability to easily and accurately scale and reference SfM models, regardless of physical site location, time, or access to a TDS. Although this technique of establishing GCPs has been used mainly on permanent bedrock features, it also has far reaching applications for survey level data collection and artifact documentation. 


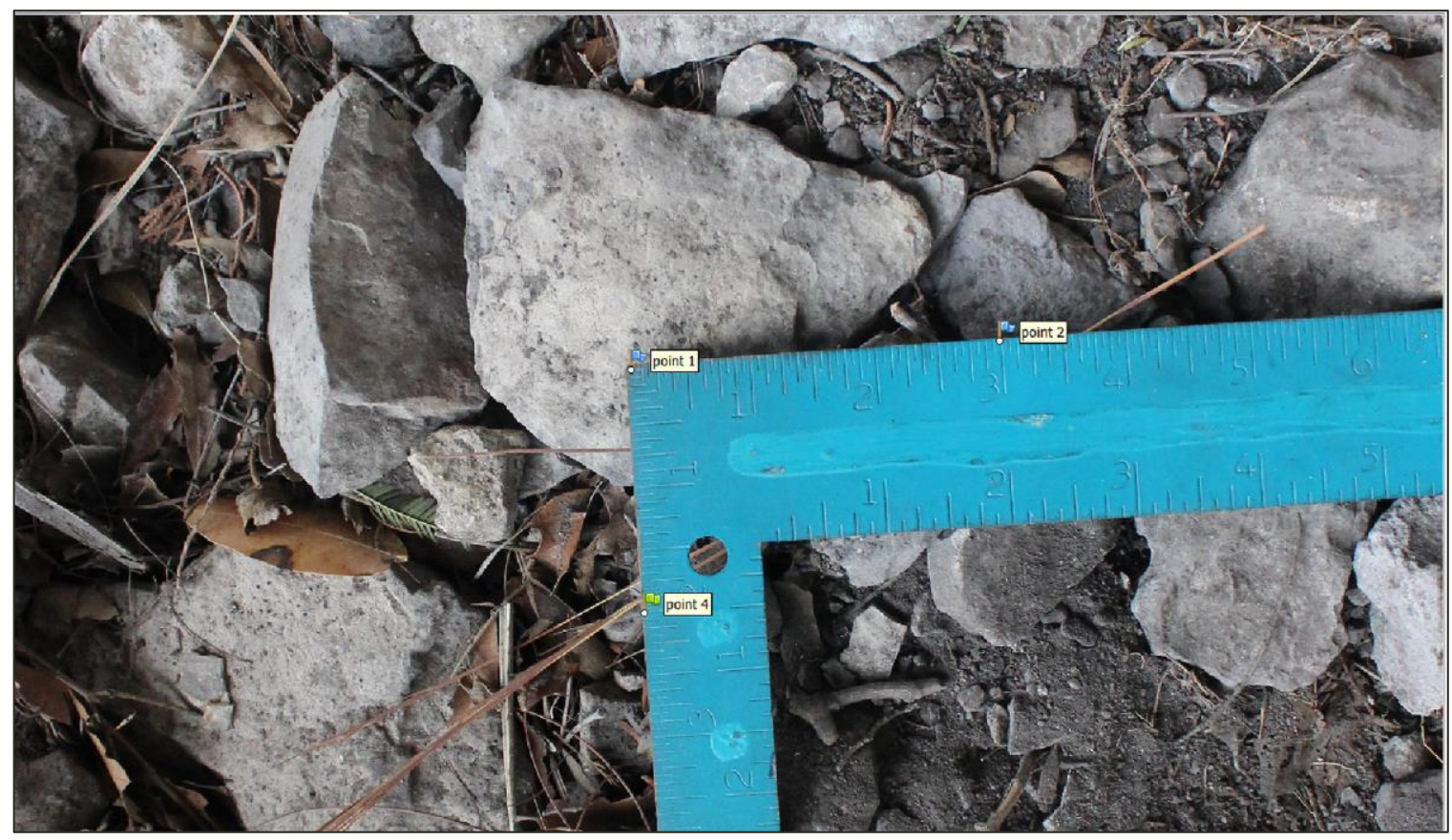

Figure 19. In Photoscan, GCPs are digitally placed directly onto the ruler. Because the units on the ruler correspond to real-world measurements, GCPs can be converted easily from inches to meters.

Table 3. GCP coordinates placed on the Builder's Square in Photoscan and Calculated Error

\begin{tabular}{lcccc}
\hline \multirow{2}{*}{ Ground Control Points } & \multicolumn{3}{c}{ Arbitrary GCP Coordinates } & \multicolumn{2}{c}{ Calculated Error in Photoscan } \\
\cline { 2 - 5 } & $\mathbf{X}(\mathrm{m})$ & $\mathbf{Y}(\mathbf{m})$ & $\mathbf{Z}(\mathbf{m})$ & Error $(\mathbf{m m})$ \\
\hline GCP1 & 100.0000 & 100.0000 & 100.0000 & 0.9 \\
GCP2 & 100.0762 & 100.0000 & 100.0000 & 0.5 \\
GCP3 & 100.2540 & 100.0000 & 100.0000 & 0.3 \\
GCP4 & 100.0000 & 100.0508 & 100.0000 & 0.6 \\
GCP5 & 100.0000 & 100.1524 & 100.0000 & 0.3 \\
GCP6 & 100.1778 & 100.0000 & 100.0000 & 0.3 \\
Total Error & & & & $\mathbf{0 . 5}$ \\
\hline
\end{tabular}

*Error value represents a RMS value

\section{ANALYTICAL APPLICATIONS}

The previous examples demonstrate SfM's capabilities for producing highly accurate site, feature, and stratigraphic maps from a variety of platforms. Yet, maps represent only one use of SfM data. Just like recording sites and excavation areas using a TDS, SfM documentation allows archeologists to collect accurate and very precise spatial data that can be used for spatial analyses (Draeyer and Strecha 2014). Below several different analytical applications are considered 


\section{Aerial Reconnaissance}

Just as multi-spectral satellite imagery has been used to help identify archeological site locations from outer space (Comer and Harrower 2013), the same techniques can be applied on a smaller scale with UAVs. Aerial photography platforms can easily be equipped with Near Infra-red (NIR), thermal, and other types of sensors (Verhoeven 2008) to identify archeological phenomena that are not visible to the unaided eye. Borrowing from the existing body of work related to remote-sensing with satellites, the same approaches can be applied to studying landscapes via UAVs. UAVs can fly a survey area much quicker than a crew conducting pedestrian survey and have the potential to identify features that may not be readily apparent from the ground. Feature identification may also be enhanced by the three-dimensional data generated from the ground surface with SfM and further augmented with multispectral data. While the use of UAVs will never replace the need for pedestrian surveys, it can be used to inform and guide research so that archeologists can focus resources more efficiently. The synergistic use of existing survey technologies with advances in 3D modeling and UAV capabilities has great potential to broaden our understanding of prehistoric landscapes (Willis 2013).

\section{Spatial Analyses}

The higher the resolution of spatial data collected, the more detailed analyses can become. This is especially true regarding modelling and analysis using GIS. In many cases, archeologists only have access to a 10-meter resolution DEM; in other words, the height of the ground surface over a $100 \mathrm{~m}^{2}$ is averaged into a single "pixel" on the DEM. By using SfM to create DEMs with less than $10 \mathrm{~cm}$ resolution, you increase the accuracy of spatial analyses and models. Below are several different examples of spatial analyses that can be conducted using SfM data.

\section{Volumetric Calculations}

Because of the accuracy of SfM data, researchers can use different tools in GIS to accurately calculate volumes. It can be used to calculate the total sediment removed from an excavation unit (see Figure 15), or even calculate the volume of a feature. The use of GIS tools removes some of the error associated with calculating the geometry of an amorphous 3D shape. We recently used SfM data to calculate the volume of several burned rock middens in the Lower Pecos. Prior to aforementioned UAV coverage of Rancid Cactus (see Figure 8), PAP was used to map the surface of the site, followed by ground-based photography to document the completed excavation unit floors and walls. With 3D models of these two surfaces, the volume of the BRM (Figure 20) was calculated using Cut Fill in ArcGIS. Archeologists using such an approach can accurately calculate the volume of irregular shapes, obviating the necessity of arbitrary metric excavation (see also Magnani and Schroder 2015). 


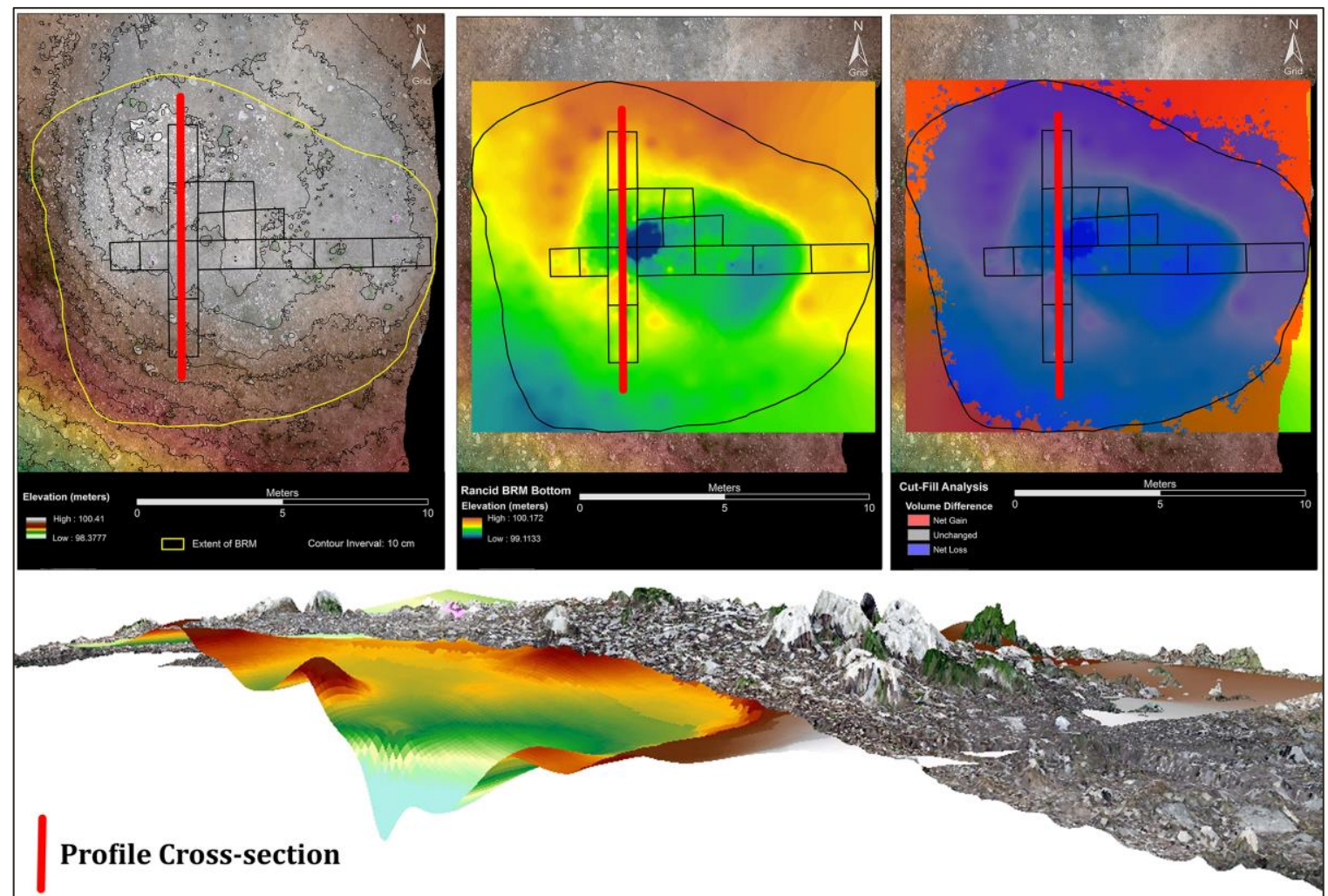

Figure 20. Calculating the volume of a burned rock midden using SFM and GIS. The original ground surface of Rancid Cactus (41VV2053) was photographed using PAP to finer than $2 \mathrm{~cm}$ resolution (top left). Once excavations were completed, the bottom of the units were modeled to map base of the BRM feature (top center). The deep depression visible in the DEM is where the central cooking pit of the BRM was located, and where our excavations went the deepest (over a meter below surface). Using the CutFill tool in ArcMap 10.2 (top left), the volume of the BRM was calculated to be approximately $24 \mathrm{~m} 3$ by measuring the difference between the ground surface and the bottom of the BRM. The two surfaces are shown bisected in ArcScene (bottom) with $2 x$ vertical exaggeration.

\section{Change Detection}

Following in the same vein as volumetric calculations, one of the more exciting aspects of SfM data is the ability to track site, feature, or even artifact condition over time (Willis 2011). By creating SfM models of subjects at different times, the change in surface topography can be monitored using $\mathrm{SfM}$. This can be applied to landscapes to monitor how much of a site is being eroded each year, or on smaller scales like individual figures within a pictograph panel (Figure 21).

\section{Morphological Studies}

3D modeling has also been used to document and study artifacts. 3D scanners are more commonly used, but SfM can provide similar data. For instance, a recent study of Caddo ceramics used 3D scanning and 3D geometric morphometrics to determine the variation within Caddo ceramics (Selden et al. 2014). Castañeda and Willis have been using SfM to document similar morphological variations of bedrock grinding features in the Lower Pecos and the western United States (Figure 22). These studies allow for shapes and sizes of the bedrock feature 3D models to be 
compared statistically and without direct human categorization. This may lead to new typologies that were impossible to recognize using traditional methods.

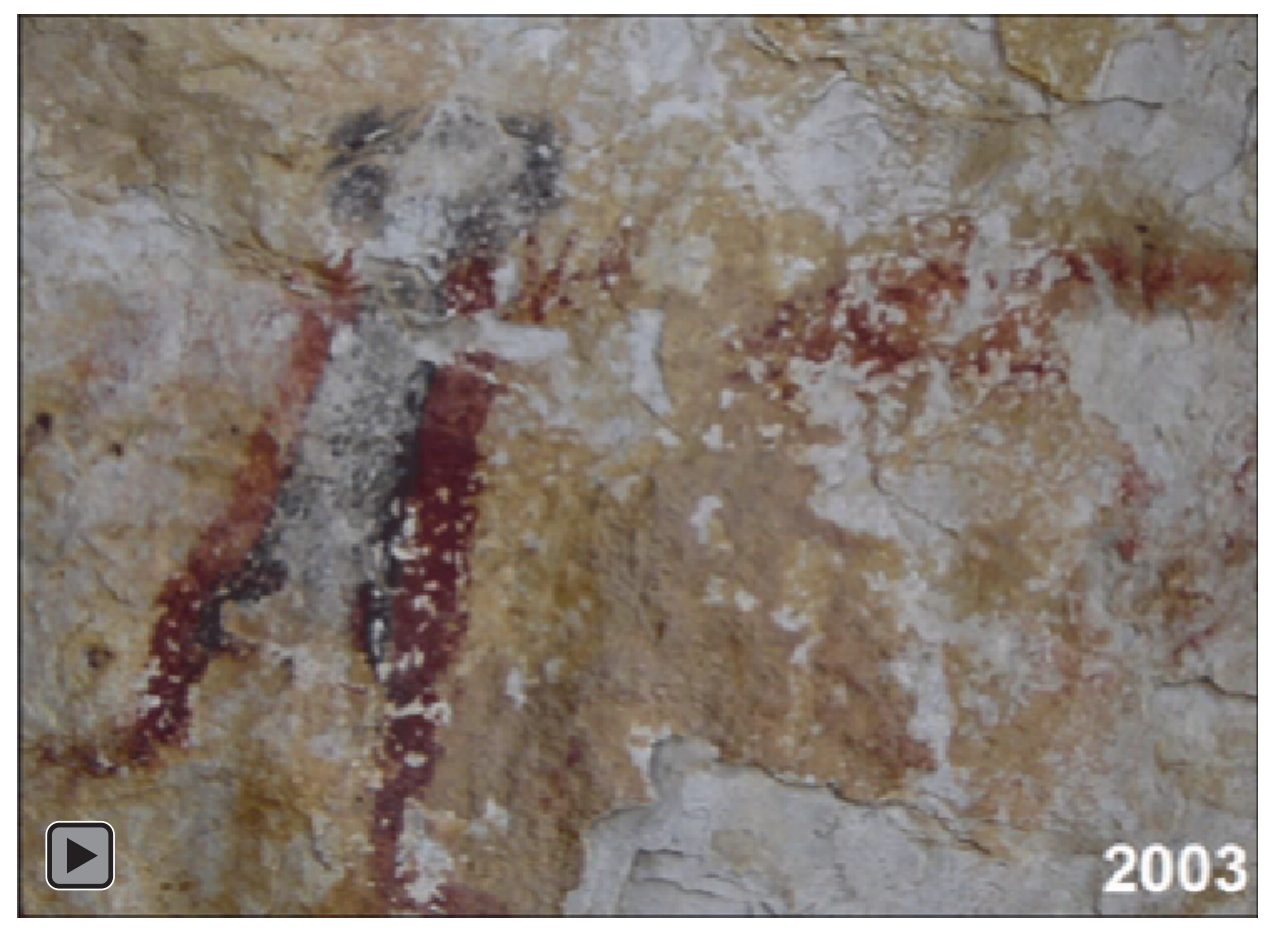

Figure 21. Change detection is able to show areas of loss/gain on surfaces ranging from rockshelter walls to entire drainage basins. This figure is an animation of the change in a single pictographic figure from 41CX2. Click image to enable playback.

\section{Additional GIS Applications}

Producing predictive models for site locations and using GIS to model existing site locations is becoming common (e.g., Mehrer and Wescott 2005). The accuracy of any predictive model, however, depends on the resolution of the spatial data. High-resolution SfM models can improve the results because there is drastically less surface-averaging using a DEM with 3-centimeter accuracy rather than 10-meter. Erosion and soil loss modeling (e.g., Cochrane and Flanagan 1999; Jain and Kothyari 2000; Lim et al. 2005; Mitasova et al. 1996), least-cost-pathway analyses (e.g., Byerly et al. 2005; Carlson and Bement 2013), and view shed analysis can benefit from the higher-resolution landscape data SfM can provide. 


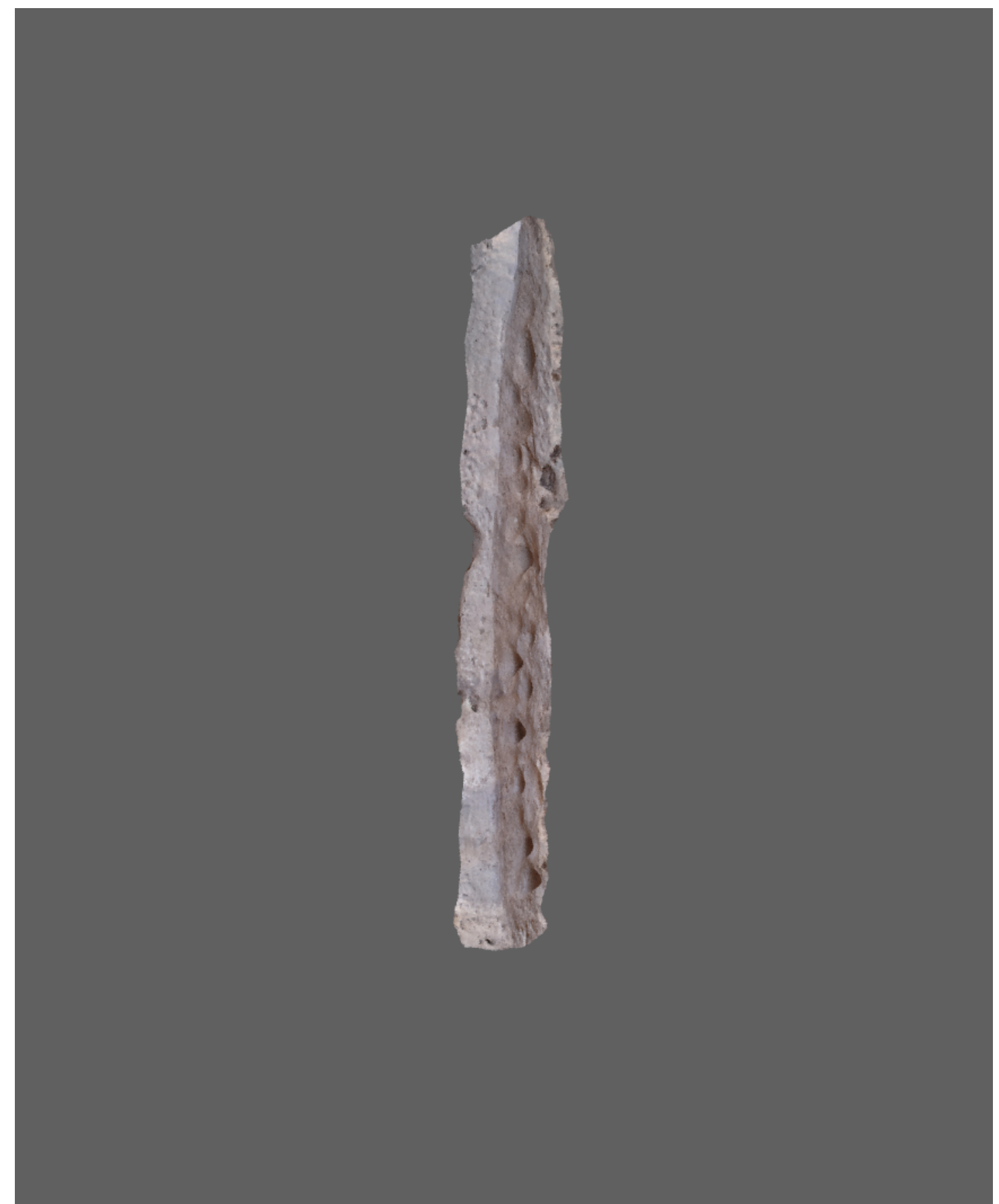

Figure 22. 3D model of a series of 27 bedrock features from Mountain Laurel Shelter (41W2010). 3D model generated from 80 photographs. This model can be rotated, measured, and otherwise manipulated by clicking the image.

Because it is in a 3D format, it can be used for morphological studies. Due to size constraints, the texture resolution is only $25 \%$ of the original. Click image to enable interactive content. 


\section{EQUIPMENT CONSIDERATIONS}

As should be apparent, there is no one-size-fits-all list of the necessary equipment. It varies greatly dependent on the platform, setting, desired resolution, turnaround time, and so on. In addition to ordinary field and research equipment (such as a TDS, computer, etc.), the minimal requirement is a basic digital camera and the processing software. Increasingly there are open-source programs that can do the processing, but Photoscan and other proprietary software better suit our needs. While a decent 3D model can be generated from photographs taken from a cheap digital camera, higher quality cameras are needed when SfM documentation is used daily. In the challenging light conditions presented by rockshelter (or deep unit) excavation, we have found that a digital SLR or mirrorless camera with a fast lens allows us to rapidly take SfM sets in poor lighting. Similarly, processing large SfM sets can be done with only an ordinary laptop, but it can take many hours of processing time. To expediently process multiple SfM sets, a powerful workstation with high end graphics cards and lots of RAM (128 Gb and greater) is highly desirable. But, any archaeologist can join the SfM revolution on the cheap and, down the road, add higher quality and more powerful equipment

\section{CONCLUSION}

The SfM methodological revolution is unfolding at a breath-taking pace by a growing, yet still small number of archeologists across the globe. Methodological innovations and new applications of SfM technology are constantly being developed as knowledgeable individuals take the revolution to many different archeological contexts and documentary challenges. Hopefully this article will alert more archeologists to the as-yet scarcely tapped potential that the SfM revolution is bringing to archeology. In our view, SfM should not be reserved for monumental and extraordinary archeological discoveries, but instead applied to many different dimensions of routine archeological documentation. However, like other techniques in archeology, SfM cannot be used in isolation. It should be regarded much like other new innovations used to better understand, document, and preserve the past. In the years to come ground-based SfM applications should allow North American archeologists to escape the self-imposed bonds of arbitrary metric excavation. Small square holes have defined and confined archeologists for far too long (Koenig et al. 2016).

We repeat our call to all field archeologists: start taking systematic sequential sets of digital photographs of all critical and fleeting archeological exposures. You may not have the time, software, or technological inclination to process the photographic data and create $3 \mathrm{D}$ models when you are in the field, but these steps can be taken years or decades later if you capture and preserve the essential data. The technology has the capacity to transform and improve many aspects of essential archeological field (and laboratory) documentation and open new interpretive windows. We predict it will do just that as SfM unfolds the way most digital technologies do: the necessary hardware and software will become cheaper, more powerful, and easier to use, thus driving innovation and incorporation with other technologies. Cultural resource managers and researchers will increasingly employ SfM models to create compelling interpretive and public outreach graphics, to highlight preservation efforts, and to monitor and quantify resource damage assessments. Archeological SfM 
models are now being used to create augmented reality (AR) views of the real-world environment (Rua and Alvito 2011), making it possible for us to walk through a previously excavated site while holding a mobile computing device. Other SfM datasets are turned into animations that allow viewers to watch as excavation exposures appear on the screen, just as they did while the work was being done. The future of archeological documentation, analysis and interpretation is multi-dimensional and graphically vivid.

\section{ACKNOWLEDGMENTS}

The Ancient Southwest Texas project case studies presented in this article would not have been possible without the Thomas E. Miller Endowment. We would like to thank several colleagues and organizations who have assisted us: Timothy Graves and Miles Miller of Versar, Inc., Carolyn Boyd and the staff of Shumla Archaeological Research and Education Center, Andy Cloud and staff at the Center for Big Bend Studies at Sul Ross University, and Brian Knight of the Environmental Division of Directorate of Publics Works at Fort Bliss. We are grateful for the insightful comments provided by JTAH editor, Todd Ahlman, and the anonymous reviewers who helped improve the article over earlier versions.

\section{REFERENCES CITED}

Agisoft LLC

2014 Agisoft Photoscan User Manual: Professional Edition, Version 1.1. http://www.agisoft.com/downloads/user-manuals/

2015 Agisoft Photoscan Professional Edition, Version 1.1.6. http://www.agisoft.com/features/professional-edition/

Athens, J. Stephen, Alex Morrison, and Mark Willis

2015 Low Sitios con Tolas de la Hacienda Zuleta y de Cochasqui: Investigaciones 2013. International Archaeological Research Institute, INC. Honolulu, Hawaii.

Basham, G. Matt

2015 Subsistence Strategies and Landscape Use in the Canyon Edge Zone: Eagle Nest Canyon, Langtry, Texas. Unpublished Master's Thesis, Department of Anthropology, Texas State University.

Brandon, R. Joe

2012 Kites for low cost near earth aerial archaeological photography. Unpublished Master's Thesis, Department of Anthropology, University of Arkansas.

Brown, David O, Camino Camino, and Mark D. Willis

2010 Algunas Observaciones a las Fortalezas Incas del Oeste montañoso del Ecuador. Instituto Nacional de Parrimonio Cultural: INPC - Revista del Patrimonio Cultural del Ecuador. INPC No. 2:43-56. 
Byerly, Ryan M., Judith R. Cooper, David J. Meltzer, Matthew E. Hill, and Jason M. LaBelle

2005 On Bonfire Shelter (Texas) as a Paleoindian Bison Jump: An Assessment Using GIS and Zooarchaeology. American Antiquity 70(4):595-629.

Campbell, John.

2012 Modeling Burned Rock Features as Units of Subsistence Intensification. Unpublished Master's Thesis, Department of Anthropology, Texas State University.

Carlson, Kristen and Leland Bement

2013 Organization of bison hunting at the Pleistocene/Holocene transition on the Plains of North America. Quaternary International 297: 93-99.

Castañeda, Amanda M.

2015 The Hole Story: Understanding Bedrock Feature Variation in the Lower Pecos Canyonlands. Unpublished Master's Thesis, Department of Anthropology, Texas State University, San Marcos.

Chandler, Jim H. and Fryer, J.G.

2005 Recording aboriginal rock art using cheap digital cameras and digital photogrammetry. CIPA 2005 XX International Symposium, 26. September - 01 October, 2005, Torino, Italy.

Cochrane, T. A. and D.C. Flanagan

1999 Assessing water erosion in small watersheds using WEPP with GIS and digital elevation models. Journal of Soil and Water Conservation 54(4):678-685.

Comer, Douglas C. and Michael J. Harrower

2013 Mapping Archaeological Landscapes from Space. Springer Briefs in Archaeology. Archaeological Heritage Management. International Committee on Archaeological Heritage Management (ICAHM). Baltimore, MD, USA

De Reu, Jeroen, Gertjan Plets, Geert Verhoeven, Philippe De Smedt, Machteld Bats, Bart Cherretté, Wouter De Maeyer, Jasper Deconynck, Davy Herremans, Pieter Laloo, Marc Van Meirvenne, and Wim De Clercq

2013 Towards a three-dimensional cost-effective registration of the archaeological heritage. Journal of Archaeological Science 40:1108-1121.

De Reu, Jeroen, Philippe De Smedt, Davy Herremans, Marc Van Meirvenne, Pieter Laloo, and Wim De Clercq

2014 On introducing an image-based 3D reconstruction method in archaeological excavation practice. Journal of Archaeological Science 41:251-262.

Douglass, Matthew, Sam Lin, and Michael Chodoronek

2015 The Application of 3D Photogrammetry for In-Field Documentation of Archaeological Features. Advances in Archaeological Practice 3(2):136-152 
Draeyer, Bernhard and Christoph Strecha

2014 White paper: How accurate are UAV surveying methods?

Pix4D. Bern, Switzerland.

Drap, Pierre

2012 Underwater Photogrammetry for Archaeology. In Special Applications of Photogrammetry, edited by Daniel Carneiro da Silva. pp. 111-136. InTech, DOI: 10.5772/33999. Retrieved from: http://www.intechopen.com/books/special-applications-of-photogrammetry/underwaterphotogrammetry-for-archaeology, accessed, February 1, 2016.

Dreyer-Lynch, Elizabeth

2014 Prehistoric Grinding Landscapes of the Southern Plains: The Archaeology of Bedrock Ground Stone Features in the Chaquaqua Plateau in Southeastern Colorado. Unpublished Ph.D. dissertation, Department of Anthropology, The University of Wyoming, Laramie.

Furukawa, Yasutaka and Jean Ponce

2007 Accurate, Dense, and Robust Multi-View Stereopsis. IEEE Computer Society Conference on Computer Vision and Pattern Recognition.

Graves, Tim, Juan Arias, and Mark Willis

2013 Guadalupe Village (LA 143472), A Burned Rock Midden Site in Southeastern New Mexico and the Use of Innovative and Inexpensive Mapping Techniques. In Advances in Jornada Mogollon Archaeology: Papers from the 17th Jornada Mogollon Conference, edited by T.L. VanPool, E.M. McCarthy, and C.S. Van Pool, pp. 17-40. El Paso Museum of Archaeology, El Paso.

Green, Susie, Andrew Bavan, and Michael Shapland

2014 A comparative assessment of structure from motion methods for archaeological research. Journal of Archaeological Science 46(2014):173-181.

Houk, Brett A. (editor)

2013 The 2013 Season of the Chan Chich Archaeological Project. Papers of the Chan Chich Archaeological Project, Number 7. Department of Sociology, Anthropology, and Social Work. Texas Tech University. Lubbock, Texas.

Jain, Manoj K. and Umesh C. Kothyari

2000 Estimation of soil erosion and sediment yield using GIS. Hydrological Sciences Journal 45(5):771-786.

Kenmotsu, Nancy A., Leonard Kemp, and Lawrence L. Loendorf

2012 Jornada Rockshelters as Special Places: Investigations of 13 Sites along the Otero Mesa Escarpment, Fort Bliss Military Reservation, Otero County, New Mexico. Historic and Natural Resources Reports Nos. 11-12 and 11-26, Environmental Division, Fort Bliss Garrison Command, Fort Bliss, Texas. 
Kjellman, Erik

2012 From $2 D$ to $3 D$ - A photogrammetric revolution in archaeology? Unpublished Master's Thesis, Department of Archaeology and Social Anthropology, University of Tromsø.

Koenig, Charles W.

2012 Burned Rock Middens, Settlement Patterns, and Bias in the Lower Pecos Canyonlands of Texas. Unpublished Master's Thesis, Department of Anthropology, Texas State University.

Koenig, Charles W., Mark D. Willis, and Stephen L. Black

2016 Beyond the Square Hole: Application of Structure from Motion Photogrammetry to Archaeological Excavation. Advances in Archaeological Practice, in press.

Liebman, Matt, Chester Walker, and Jennie Sturm

2013 Mapping Archaeological Sites Using an Unmanned Aerial Vehicle. Newsletter of the New Mexico Archeological Council. Albuquerque, New Mexico.

Lim, Kyoung Jae, Myung Sagong, Bernard A. Engel, Zhenxu Tang, Joongdae Choi, and Ki-Sung Kim

2005 GIS-based sediment assessment tool. Catena 64:61-80.

Lin, Albert Yu-Min, Alexandre Novo, Shay Har-Noy, Nathan D. Ricklin, and Kostas Stamatiou 2011 Combining GeoEye-1 Satellite Remote Sensing, UAV Aerial Imagin, and Geophysical Surveys in Anomaly Detection Applied to Archaeology. IEEE Journal of Selected Topics in Applied Earth Observations and Remote Sensing, in press.

Lowe, David G.

1999 Object recognition from local scale-invariant features. Proceedings of the International Conference on Computer Vision 2:1150-1157. doi:10.1109/ICCV.1999.790410.

Magnani, Matthew and Wittaker Schroder

2015 New Approaches to Modeling the Volume of Earthen Archaeological Features: A CaseStudy from the Hopewell Culture Mounds. Journal of Archaeological Science 64:12-21.

Manaugh, Geoff

2013 36-Gigapixel Image Captures Ancient Petroglyphs in Texas. Gizmodo Retrieved from http://gizmodo.com/36-gigapixel-image-captures-ancient-petroglyphs-in-texa-1410698528, accessed, February 1, 2016.

McCarthy, John.

2014 Multi-image photogrammetry as a practical tool for cultural heritage survey and community engagement. Journal of Archaeological Science 43:175-185.

Miller, Myles R., Lawrence L. Loendorf, and Leonard Kemp

2012 Picture Cave and Other Rock Art Sites on Fort Bliss. Historic and Natural Resources Report No. 13-36, Environmental Division, Fort Bliss Garrison Command, Fort Bliss, Texas. 
Miller, Myles R. and Tim B. Graves

2009 Madera Quemada Pueblo: Archaeological Investigations at a 14th Century Jornada Mogollon Pueblo. Historic and Natural Resources Report No. 03-12, Environmental Division, Fort Bliss Garrison Command, Fort Bliss, Texas.

Mitasova, Helena, Jaroslav Hofierka, Maros Zlocha, and Louis R. Iverson

1996 Modelling topographic potential for erosion and deposition using GIS. International Journal of Geographical Information Systems 10(5):629-641.

Mehrer, Mark W. and Konnie L. Wescott

2005 GIS and Archaeological Site Modeling. CRC Press, Boca Raton.

Nadel, Dani, Sagi Filin, Danny Rosenberg, and Vera Miller

2015 Prehistoric Bedrock Features: Recent Advances in 3D Characterization and Geometrical Analysis. Journal of Archaeological Science 53:331-344.

Reinhard, Jochen

2012 Things on strings and complex computer algorithms: Kite Aerial Photography and Structure from Motion Photogrammetry at the Tulul adh-Dhahab, Jordan. AARGnews: The Newsletter of the Aerial Archaeology Research Group 45:37-41.

Roberts, Tim and Luis Alvarado

2011 Terminal Archaic/Late Prehistoric Cooking Technology in the Lower Pecos: Excavation of the Lost Midden Site (41VV1991), Seminole Canyon State Park and Historic Site, Val Verde County, Texas. Texas Antiquities Permit No. 4868. Texas Parks and Wildlife Department Cultural Resources Program, Austin, Texas.

Rodriguez, Daniel P.

2015 Patterns in the Use of the Rockshelters of Eagle Nest Canyon, Langtry, Texas. Unpublished Master's Thesis, Department of Anthropology, Texas State University.

Rua, Helena and Pedro Alvito

2011 Living the past: 3D models, virtual reality and game engines as tools for supporting archaeology and the reconstruction of cultural heritage - the case study of the Roman villa of Casal de Freiria. Journal of Archaeological Science 38:3296-3308.

Selden, Robert Z. Jr., Timothy K. Perttula, and Michael J. O'Brien

2014 Advances in Documentation, Digital Curation, Virtual Exhibition, and a Test of 3D Geometric Morphometrics: A Case Study of the Vanderpool Vessels from the Ancestral Caddo Territory. Advances in Archaeological Practice 2(2):64-79.

Verhoeven, Geert

2008 Imaging the Invisible. Using modified Digital Still Cameras for Straightforward and LowCost Archaeological Near-InfraRed Photography. Journal of Archaeological Science 35(12), 3087-3100. 
2009 Providing an Archaeological Bird's-eye View - an Overall Picture of Ground-based Means to Execute Low-altitude Aerial Photography (LAAP) in Archaeology. Archaeological Prospection 16:233-249.

2011 Software Review: Taking Computer Vision Aloft - Archaeological Three-dimensional Reconstructions from Aerial Photographs with PhotoScan. Archaeological Prospection 18:67-73.

Verhoeven, G., M. Doneus, Ch. Briese, and F. Vermeulen

2012 Mapping by matching: a computer vision-based approach to fast and accurate georeferencing of archaeological aerial photographs. Journal of Archaeological Science 39:2060-2070.

Willis, Mark D.

2010 How to create a Digital Elevation Model from Photosynth Point Clouds. Markaeology. Retrieved from http://palentier.blogspot.com/2010/12/how-to-create-digital-elevation-model.html ¿accessed, February 1, 2016.

2011 Determining Rock Art Deterioration Through Time: Automatic Change Detection with SfM. Markaeology. Retrieved from http://palentier.blogspot.com/2011/11/determining-rock-artdeterioration.html, accessed, February 1, 2016.

2013 Drone Mapping the Pyramids of Zuleta. Markeology. Retrieved from http://palentier.blogspot.com/2013/10/drone-mapping-pyramids-of-zuleta.html , accessed, February 1, 2016.

Willis, Mark D., Brett A. Houk, Kelsey Herndon, and Chet Walker

2014 Structure from Motion Mapping of Structure A-15 at Chan Chich. In The 2014 Season of the Chan Chich Archaeological Project, edited by Brett A. Houk, pp. 21-30. Papers of the Chan Chich Archaeological Project, Number 8. Department of Sociology, Anthropology, and Social Work. Texas Tech University, Lubbock.

Willis, Mark D. and Andrea Jalandoni

2011 The Pictographs of the Rock Islands of Koror, Palau: Advanced Enhancement and 3D Modeling at Five Sites for UNESCO. Unpublished report submitted to Ministry of Community \& Cultural Affairs of Palau. 